\title{
In-situ incubation of a coral patch for community-scale assessment of metabolic and chemical processes on a reef slope
}

\author{
Steven M.A.C. van Heuven ${ }^{1}$, Alice E. Webb ${ }^{1}$, Didier M. de Bakker ${ }^{2,3}{ }^{\text {, Erik Meesters }}{ }^{3}$, Fleur C. van Duyl ${ }^{2}$, \\ Gert-Jan Reichart ${ }^{1,4}$, Lennart J. de Nooijer ${ }^{\text {Corresp. } 1}$ \\ 1 Department of Ocean Sciences, NIOZ Royal Netherlands Institute for Sea Research, and Utrecht University, Den Hoorn, Noord-Holland, The Netherlands \\ 3 Wageningen Marine Research, Wageningen University and Research, Den Helder, Noord-Holland, The Netherlands \\ 4 Department of Earth Sciences, Utrecht University, Utrecht, Utrecht, Netherlands
}

Corresponding Author: Lennart J. de Nooijer

Email address: Idenooijer@nioz.nl

Anthropogenic pressures threaten the health of coral reefs globally. Some of these pressures directly affect coral functioning, while others are indirect, for example by promoting the capacity of bioeroders to dissolve coral aragonite. To assess the coral reef status, it is necessary to validate community-scale measurements of metabolic and geochemical processes in the field, by determining fluxes from enclosed coral reef patches. Here, we investigate diurnal trends of carbonate chemistry, dissolved organic carbon, oxygen and nutrients on a 20 meter deep coral reef patch offshore from the island of Saba, Dutch Caribbean by means of tent incubations. The obtained trends are related to benthic carbon fluxes by quantifying net community calcification (NCC) and net community production (NCP). The relatively strong currents and swell-induced near-bottom surge at this location caused minor seawater exchange between the incubated reef and ambient water. Employing a compensating interpretive model, the exchange is used to our advantage as it maintains reasonably ventilated conditions, which conceivably prevents metabolic arrest during incubation periods of multiple hours. No diurnal trends in carbonate chemistry were detected and all net diurnal rates of production were strongly skewed towards respiration suggesting net heterotrophy in all incubations. The NCC inferred from our incubations ranges from -0.57 to $3.20 \mathrm{mmol} \mathrm{CaCO}_{3} \mathrm{~m}^{-2} \mathrm{~h}^{-1}(-0.5$ to $2.8 \mathrm{~kg}$ $\mathrm{CaCO}_{3} \mathrm{~m}^{-2} \mathrm{yr}^{-1}$ ) and NCP varies from $-9 \mathrm{mmol} \mathrm{m}^{-2} \mathrm{~h}^{-1}$ to $-21.7 \mathrm{mmol} \mathrm{m}^{-2} \mathrm{~h}^{-1}$ (net respiration). When comparing to the consensus-based ReefBudget approach, the estimated net community calcification rate for the incubated full planar area $\left(0.36 \mathrm{~kg} \mathrm{CaCO}_{3} \mathrm{~m}^{-2} \mathrm{yr}^{-1}\right)$ was lower, but still within range of the different NCC inferred from our incubations. Field trials indicate that the tent-based incubation as presented here, coupled with an appropriate interpretive model, is an effective tool to investigate, in-situ, the state of coral reef patches 
even when located in a relatively hydrodynamic environment. 


\title{
In-situ incubation of a coral patch for community-scale assessment of metabolic and chemical processes on a reef slope
}

\author{
Steven M. A. C. van Heuven ${ }^{*}$, Alice E Webb ${ }^{1 *}$, Didier M. de Bakker ${ }^{2,3}$, Erik Meesters ${ }^{3}$, Fleur C. van \\ Duyl $^{2}$, Gert-Jan Reichart ${ }^{1,4}$, Lennart J. de Nooijer ${ }^{1}$ \\ 1) NIOZ Royal Netherlands Institute for Sea Research, and Utrecht University, Department of Ocean Sciences \\ 2) NIOZ Royal Netherlands Institute for Sea Research, and Utrecht University, Department of Marine Microbiology \\ 3) Wageningen Marine Research, Den Helder, The Netherlands \\ 4) Department of Earth Sciences, Utrecht University, Utrecht, The Netherlands \\ * These authors contributed equally to this work.
}

\section{Abstract}

Anthropogenic pressures threaten the health of coral reefs globally. Some of these pressures directly affect coral functioning, while others are indirect, for example by promoting the capacity of bioeroders to dissolve coral aragonite. To assess the coral reef status, it is necessary to validate community-scale measurements of metabolic and geochemical processes in the field, by determining fluxes from enclosed coral reef patches. Here, we investigate diurnal trends of carbonate chemistry, dissolved organic carbon, oxygen and nutrients on a 20 meter deep coral reef patch offshore from the island of Saba, Dutch Caribbean by means of tent incubations. The obtained trends are related to benthic carbon fluxes by quantifying net community calcification (NCC) and net community production (NCP). The relatively strong currents and swell-induced near-bottom surge at this location caused minor seawater exchange between the incubated reef and ambient water. Employing a compensating interpretive model, the exchange is used to our advantage as it maintains reasonably ventilated conditions, which conceivably prevents metabolic arrest during incubation periods of multiple hours. No diurnal trends in carbonate chemistry were detected and all net diurnal rates of production were strongly skewed towards respiration suggesting net heterotrophy in all incubations. The $\mathrm{NCC}$ inferred from our incubations ranges from -0.57 to $3.20 \mathrm{mmol} \mathrm{CaCO}_{3} \mathrm{~m}^{-2} \mathrm{~h}^{-1}$ (-0.5 to $2.8 \mathrm{~kg} \mathrm{CaCO}$ $\mathrm{m}^{-2} \mathrm{yr}^{-1}$ ) and NCP varies from $-9 \mathrm{mmol} \mathrm{m}^{-2} \mathrm{~h}^{-1}$ to $-21.7 \mathrm{mmol} \mathrm{m}^{-2} \mathrm{~h}^{-1}$ (net respiration). When comparing to the consensus-based ReefBudget approach, the estimated net community calcification rate for the incubated full planar area $\left(0.36 \mathrm{~kg} \mathrm{CaCO}_{3} \mathrm{~m}^{-2} \mathrm{yr}^{-1}\right)$ was lower, but still within range of the different $\mathrm{NCC}$ inferred from our incubations. Field trials indicate that the tent-based incubation as presented here, coupled with an appropriate interpretive model, is an effective tool to investigate, in-situ, the state of coral reef patches even when located in a relatively hydrodynamic environment.

\section{Introduction}

The functionality of many reef systems is intrinsically linked to their structural habitat complexity (Newman et al., 2006; Graham and Nash, 2013; Kennedy et al., 2013). On tropical coral reefs, the 3dimensional habitat relies primarily on the ability of corals to deposit large quantities of calcium carbonate. Over recent decades, corals reefs have been under threat at a global scale by a large number of anthropogenic impacts such as ocean warming, overfishing, eutrophication and ocean acidification (Hoegh Guldberg, 1999; Gardner et al., 2003; Hoegh Guldberg et al., 2007; De'ath et al., 2012).

The consequential decline in coral cover and the reduction in historically dominant framework building coral species has already resulted in a substantial loss of 3D-complexity on many tropical reefs (Edinger and Risk 2000; Alvarez-Filip et al. 2011a; Perry et al. 2015b; De Bakker et al. 2016).

The impact of individual aspects of environmental change on coral reef health has been assessed in a number of laboratory experiments (e.g. Gilmour, 1999; Burkepile and Hay, 2009). However, in-situ community-scale measurements of metabolic and geochemical processes would enable characterization of total reef metabolism. Net community calcification (NCC) is considered to reflect the overall response of the community to environmental change and is therefore monitored as a proxy for coral reefs' status 
51

52

53

54

55

56

57

58

59

60

61

62

63

64

65

66

67

68

69

70

71

72

73

74

75

76

77

78

79

80

81

82

83

84

85

86

87

88

89

90

91

92

93

94

95

96

97

98

99

100

101

(Gattuso et al., 1993; Kleypas et al., 1999; Edinger and Risk, 2000). Field validation of coral accretion/decline is required to test whether observed experimental responses can be translated to whole ecosystems and in situ conditions. Coral reef decline or community compositional change can be estimated qualitatively from visual inspection of the same site over time (e.g. Aronson and Precht, 1997), or by digital comparison of photographs taken at intervals (Porter and Meier, 1992; Coles and Brown, 2007; De Bakker et al., 2016). The disadvantage of such visual assessments, however, is that results are confined to areas that have been visited previously and are not quantitative with respect to NCC. Still, the latter may be estimated from visual inspections using typical, species-specific calcification rates (Perry, Spencer and Kench, 2008). And although demonstrated to have fair accuracy (Porter and Meier, 1992; Alevizon and Porter, 2015; Chow et al., 2016), 'carbonate budgetting' estimates do not allow estimating seasonal variability of NCC (Courtney et al., 2016), and are inherently insensitive to rapid environmental change. The same goes for elevation-change analyses using coral cores as alone do not relate alteration in seafloor structure to cause (Hubbard, Miller and Scaturo, 1900; Yates et al., 2017). Furthermore, the integrated effects due to organismal interactions cannot be assessed with such an approach. For example, ocean acidification may reduce coral NCC (Andersson et al., 2012) and at the same time increase erosion rates by sponges (Fang et al., 2013; Webb et al. 2017). Census approach has yet to include the role of several bioeroders (excavating sponges) (Murphy et al., 2016), which have been observed to become increasingly dominant on Caribbean reefs (Chaves-Fonnegra, Zea and Gómez, 2007). Moreover, ongoing ocean acidification appears to promote the contribution of chemical $\mathrm{CaCO}_{3}$ dissolution to total bioerosion by sponges even further (e.g. Duckworth and Peterson, 2013; Whissak et al., 2013). Lastly, Silbiger et al. (2015) suggest that, under future climate conditions of increased $p \mathrm{CO}_{2}$ and ongoing warming, dissolution of existing reef carbonates is likely to be more affected than the growing of new reefs as such. Together this implies that there is an urgent need for in-situ determination of NCC at the ecosystem level.

Direct approaches to accurately quantify NCC generally rely on determining the flux of alkalinity between water column and reef (Smith and Key, 1975). For reefs in environments characterized by a relatively linear flow of water over the reef, the upstream/downstream method (Odum and Hoskins 1958; Gattuso et al., 1996) can be employed to determine NCC (e.g., Shaw et al., 2014; Koweek et al., 2015; Albright et al., 2016). For less unidirectional flow regimes, estimates based on overall residence time and knowledge of offshore conditions is needed (e.g., Courtney et al., 2016). In environments where low turbulence allows buildup of appreciable chemical vertical gradients, these gradients have been used to calculate net fluxes (e.g. McGillis et al., 2011; Takeshita et al., 2016). For fully exposed reefs, where no measurable accumulation may occur even in the boundary layer, the use of incubators is necessary. Several such incubation methods have been designed and applied. Most incubators cover a limited area (Patterson, Sebens and Olson, 1991; Haas et al., 2013; Ozaki et al., 2013; Camp et al., 2015), allowing single-species incubations. In most cases, numerous incubations are necessary to accurately capture variability between different locations on a reef in accretion/erosion and thus accurately estimate whole ecosystem NCC. When employing small-volume incubators, care must also be taken to maintain representative hydrodynamic conditions for the incubation species. Moreover, incubations must be terminated before NCC becomes depressed (for example by depletion of oxygen). Larger incubation structures (e.g. Yates and Halley, 2003) better capture variability on a community scale and convey environmental hydrodynamic conditions (surge) which, on the other hand, may cause inadvertent leakage of enclosed water. This potential exchange between ambient and enclosed water complicates the interpretation of observed chemical changes, particularly for signals that take relatively long to manifest themselves (e.g., alkalinity). The latter limitation restricts this method into hydrodynamically favorable (i.e. calm) conditions (e.g. McGillis et al., 2011). Additionally, due to obvious logistical challenges, most or all in-situ incubations have been carried out on the reef flat.

Here we aim to assess diurnal coral reef metabolic rates by investigating the in situ inorganic carbonate system over a reef slope coral reef patch offshore from the island of Saba, Dutch Caribbean. We use a tentbased incubation system in an environment with relatively strong currents and swell-induced near-bottom surge that caused modest exchange between the incubated reef and ambient water. Exchange between the enclosed and surrounding seawater is used to our advantage as this maintains oxygenated conditions during 
102

103

104

105

106

107

108

109

110

111

112

113

114

115

116

117

118

119

120

121

122

123

124

125

126

127

128

129

130

131

132

133

134

135

136

137

138

139

140

141

142

143

144

145

146

147

148

149

150

151

152

the incubation, thus allowing for increased incubation periods. Precise monitoring of temperature and salinity, both inside and outside the tent, allows for accurate determination of the amount of exchange across the enclosure. Explicitly accounting for the role of ambient variability, the benthic fluxes originating within the tent are inferred with high accuracy. Comprehensive monitoring of $\mathrm{CO}_{2}$ system parameters (DIC, total alkalinity), dissolved oxygen and nutrients (phosphate, nitrate, nitrite and ammonium) allows for subsequent quantification of integrated whole ecosystem coral reef metabolic processes (NCC and net community production, $\mathrm{NCP}$ ) in a highly hydrodynamic environment.

\section{Methods}

Site and substrate. Reef incubations were performed west of the island of Saba in Ladder Bay at the Ladder Labyrinth mooring site of the Saba National Marine Park $\left(17.6261^{\circ} \mathrm{N}, 63.2602^{\circ} \mathrm{W}\right.$ ) (Field permit approved by the Dutch Ministry of Infrastructure and Environment: RWS-2015/38370), between October $26^{\text {th }}$ and $29^{\text {th }} 2015$, at a depth of $21 \mathrm{~m}$ (Figure 1). The reef in this area has a distinct spur-and-groove morphology, and is located on a steep incline from the heights of Saba towards the $\sim 500 \mathrm{~m}$ deep stretch between the island and the Saba Bank carbonate platform. Coral reefs around Saba harbour a relatively rich diversity of marine species in the context of the wider Caribbean (Etnoyer, Wirshing and Sanchez, 2010). The location at which the tent was placed, was chosen such that a patch of coral reef with a community representative of the wider area was fully enclosed (Figure 2). Within the 2x2 m enclosure, one larger and several smaller carbonate structures were present, acting as main substratum for benthic biota, together resulting in a in a total hard surface area $\sim 4.4 \mathrm{~m}^{2}$ and a $14 \%$ surface enlargement (rugosity). Abiotic components (sand and bare rock) accounted for $61 \%$ of the total surface area within the enclosure. Algae (algal turf, Lobophora spp., Dictyota spp.) covered 22\%, sponges (among others Agelas sp. and Callyspongia plicifera) covered $7 \%$ and calcifying species such as corals (including Orbicella faviolata, Meadrina meandrites and Diploria clivosa) and crustose coralline algae covered 4.2, and 6.6\% of the total surface area, respectively (Figure 2). No macro-bioeroding organisms were visible. A small number of heterotrophic animals, including small fish, crustaceans and nudibranch, were present during the time of the incubation.

Figure 1. (a) Photograph depicting tent, umbilical cord, support divers and the dingy used for sample collection.

(b) Schematic layout of the tent and surroundings. The Island of Saba is located to the east of this location. (c) Schematic side view of the employed setup for enclosure of a small patch of coral reef. The central structure is a rigid, inflatable dome tent, held securely in place by lead bricks and guy-lines (not shown). Inside the tent are located a battery powered mixing propeller for maintaining water circulation, and analyzers for salinity (S), temperature (T), oxygen $\left(\mathrm{O}_{2}\right)$ and PAR. External to the enclosure are located another S/T analyzer, a current profiler and a pump (powered intermittently from the surface) which through an umbilical cord delivers enclosure interior water to the sea surface for sampling. Sampling of exterior water was performed either by this pump (with SCUBA divers temporarily disconnecting the connection to the tent interior) or by divers using large volume syringes. Zippers allow for opening of tent windows for re-equilibrating interior and exterior conditions between incubations.

Figure 2. Overview of the enclosed coral reef patch, after termination of the tent incubation. Yellow lines mark the extent of the tent (approximately $2 \times 2 \mathrm{~m}$ ).

Enclosure. The incubation enclosure is a custom-made, semi-hemispherical, bottomless, transparent dome tent with a square, $4 \mathrm{~m}^{2}$ footprint and $\sim 3.2 \mathrm{~m}^{3}$ volume. The tent walls consist of transparent polyvinylchloride of $0.8 \mathrm{~mm}$ thickness, with nontransparent reinforcements along the edges. The tent was inflated (on sandy sediment) by pumping water into the ribs of the dome, after which the rigid tent was carefully moved in place over the coral mound. Flaps extended $\sim 50 \mathrm{~cm}$ outward from each of the tent's four sides, allowing for proper sealing of the tent to the substrate by placing weights on the flaps. All four sides of the tent contained an opening of $\sim 0.3 \mathrm{~m}^{2}$ to allow flushing of the enclosed volume between incubations: during each incubation this opening was sealed. Water enclosed in the incubation tent was homogenized by a continuously running propeller pump (model PP20, Jebao Ltd, China). This pump was positioned close to one of the tent arches, at half the height of the tent, and generated a slight circulating

PeerJ reviewing PDF | (2018:01:23723:3:2:NEW 18 Oct 2018) 
153

154

155

156

157

158

159

160

161

162

163

164

165

166

167

168

169

170

171

172

173

174

175

176

177

178

179

180

181

182

183

184

185

186

187

188

189

190

191

192

193

194

195

196

197

198

199

200

201

202

203

turbulence, while minimizing stirring up of sediment. Effectiveness of the stirring was demonstrated by rapid and even dispersal of a small dose of injected fluorescein. Time required for initial deployment of the tent was approximately 4 hours. In total, five incubations were carried out on this location, three during the day (incubations $1,3 \& 5$ ) and two at night (incubations $2 \& 4$ ) (Table 1).

On the sandy substrate, adjacent to the main tent, a small secondary incubator was deployed. Its design is tetrahedron-shaped, and features transparent PVC-walled, rigid edges of $1 \mathrm{~m}$, with $0.5 \mathrm{~m}$ long flaps extending from bottom edge. It covers a $0.43 \mathrm{~m}^{2}$ planar surface, and encloses a 1181 volume, resembling the cBIT described by Haas et al. (2013). Due to equipment constraints, only limited monitoring of this 'sediment blank' incubator was performed by determining the total alkalinity $\left(\mathrm{A}_{\mathrm{T}}\right)$, total dissolved inorganic carbon $\left(\mathrm{C}_{\mathrm{T}}\right)$, and nutrient concentrations.

Table 1. Incubation starting and end times, duration and light. The listed PAR values are in $\mu$ mol quanta $\mathrm{m}^{-2} \mathrm{~s}^{-1}$.

In-situ measurements. Measurement of salinity (S), temperature (T), dissolved oxygen $\left(\mathrm{O}_{2}\right)$, photosynthetically active radiation (PAR) and water current conditions within the large dome-shaped tent were performed throughout the duration of the incubations (four hours). $\mathrm{S}, \mathrm{T}$ and $\mathrm{O}_{2}$ were measured at 1minute interval using an actively pumped SBE37 MicroCAT equiped with an SBE63 optical dissolved oxygen sensor (SeaBird Scientific Inc., Bellevue WA, USA). Drift of the involved sensors over the duration of our experiment was negligible, while precision $\left( \pm 1 \cdot 10^{-5}, \pm 1 \cdot 10^{-4}{ }^{\circ} \mathrm{C}, \pm 0.2 \mu \mathrm{mol} \mathrm{kg}{ }^{-1}\right.$, respectively) is orders of magnitude better than the changes in $\mathrm{S}$, $\mathrm{T}$, and $\mathrm{O}_{2}$ observed during incubations. PAR was assessed by an Odyssey light logger (Dataflow Systems PTY Ltd., Christchurch, NZ), calibrated in air against a superior instrument (Walz ULM500, Walz GmbH, Effeltrich, Germany). The MicroCAT and light logger were suspended from the apex of the enclosure at approximately half the tent's height. A second CTD unit (model CastAway, YSI Inc, Yellow Springs OH, USA) was deployed outside the tent to register ambient S and $\mathrm{T}$ during 2 out of the 5 incubations, due to logistical constraints.

Discrete Sampling. During incubations, discrete samples were collected every two hours for analysis of $\mathrm{A}_{\mathrm{T}}, \mathrm{C}_{\mathrm{T}}$, total organic carbon (TOC) and nutrients by pumping seawater from the tent interior (and, alternatingly, the exterior) up to the support vessel through a $50 \mathrm{~m}$ long $1 / 4$ " Dekabon gas-impermeable 'umbilical cord' (Figure 1). The total volume pumped upwards was $\sim 21$ per sampling event, after appropriate flushing $(\sim 21)$ of the umbilical (internal volume $\sim 0.51$ ).

Most analyses for $\mathrm{A}_{\mathrm{T}}$ were performed on-board (Caribbean Explorer II) using spectrophotometrically guided single-step acid titration (Liu et al., 2015). Additional samples for $\mathrm{A}_{\mathrm{T}}$ and $\mathrm{C}_{\mathrm{T}}$ were poisoned with $\mathrm{HgCl}_{2}$ immediately after collection (following Dickson et al., 2007) for post-cruise analysis on a VINDTA 3C instrument (Mintrop et al., 2000). Accuracy of both instruments was set using certified reference material (CRM; batch 144) supplied by Scripps Institute of Oceanography (Dickson et al., 2007). No appreciable bias in $A_{T}$ was apparent between the two instruments. On the VINDTA, a total of $\sim 125$ samples were analyzed for $C_{T}$ and $A_{T}$. Precision of replicates from the same sample bottle was $1.5 \mu \mathrm{mol} k g-1$ for $C_{T}$ and $1.0 \mu \mathrm{mol} \mathrm{kg}^{-1}$ for $\mathrm{A}_{\mathrm{T}}$ (for both instruments). However, precision for field replicates (i.e., replicates from separate bottles; $\mathrm{n}=23$ ) was $3.5 \mu \mathrm{mol} \mathrm{kg}{ }^{-1}$ for $\mathrm{C}_{\mathrm{T}}$ and $5.0 \mu \mathrm{mol} \mathrm{kg}^{-1}$ for $\mathrm{A}_{\mathrm{T}}$, possibly reflecting suboptimal sampling conditions and/or procedures (e.g., insufficient pre-flushing of umbilical before commencing filling of $1^{\text {st }}$ replicate sample).

Samples for TOC determination were stored in pre-combusted $60 \mathrm{ml}$ EPA vials and acidified and preserved with $8 \mathrm{M} \mathrm{HCl}$ prior to shore-based analysis on a Shimadzu TOC- $\mathrm{V}_{\mathrm{CPN}}$. Analytical precision for TOC (defined as standard deviation of differences between replicates) was $\pm 9.9 \mu \mathrm{mol} \mathrm{kg}^{-1}(\mathrm{n}=8)$.

Samples for dissolved inorganic macronutrients $\left(\mathrm{NO}_{2}+\mathrm{NO}_{3}, \mathrm{NO}_{2}, \mathrm{PO}_{4}\right.$ and $\left.\mathrm{NH}_{4}\right)$ were prepared by dispensing sampled water through $0.8 / 0.2 \mu \mathrm{m}$ Acrodisk filters into $5 \mathrm{ml}$ 'pony vials', and subsequently stored at $-80^{\circ} \mathrm{C}$ for later analysis at $\mathrm{NIOZ}$ on a QuAAtro continuous flow analyser (SEAL Analytical, $\mathrm{GmbH}$, Norderstedt, Germany) following GO-SHIP protocol (Hydes et al., 2010). Uncertainty of nutrient determinations $\left( \pm 0.1 \mu \mathrm{mol} \mathrm{kg} \mathrm{kg}^{-1}, \pm 0.01 \mu \mathrm{mol} \mathrm{kg}{ }^{-1}, \pm 0.005 \mu \mathrm{mol} \mathrm{kg}-1\right.$-and $\pm 0.005 \mu \mathrm{mol} \mathrm{kg}{ }^{-1}$, respectively) was substantially smaller than the differences observed between samples taken over the incubation period.

PeerJ reviewing PDF | (2018:01:23723:3:2:NEW 18 Oct 2018) 
204

205

206

207

208

209

210

211

212

213

214

215

216

217

218

219

220

221

222

223

224

225

226

227

228

229

230

231

232

233

234

235

236

237

238

239

240

241

242

243

244

245

246

247

248

249

250

251

252

253

254

Release of nutrients during respiration decreases $\mathrm{A}_{\mathrm{T}}$ (or increases $\mathrm{A}_{\mathrm{T}}$ for release of $\mathrm{NH}_{4}{ }^{+}$), confounding the interpretation of changes in $\mathrm{A}_{\mathrm{T}}$ to represent $\mathrm{CaCO}_{3}$ dissolution only. Following common protocol, we correct calculated $\mathrm{A}_{\mathrm{T}}$ for nutrient release as follows:

$\mathrm{A}_{\mathrm{T}}{ }^{\mathrm{obsNC}}=\mathrm{A}_{\mathrm{T}}{ }^{\mathrm{obs}}+\mathrm{PO}_{4}+\mathrm{NO}_{3}-\mathrm{NH}_{4}$.

Throughout the remainder of the manuscript, $\mathrm{A}_{\mathrm{T}}$ equals $\mathrm{A}_{\mathrm{T}}{ }^{\mathrm{obsNC}}$ as defined above.

\section{Outline of data processing}

After data collection, a 6-step approach was taken to infer fluxes from the measurements. Numbered steps are discussed in more detail in the following sections. Briefly, (1) the leak rate of the enclosure is inferred from measurements of $\mathrm{S}$ and $\mathrm{T}$ performed simultaneously inside and outside the tent during 2 of the 5 incubations. (2) Assuming the inferred leak rate to be valid throughout the experiment (i.e. for the other 3 incubations as well), time series of exterior $\mathrm{S}$ and $\mathrm{T}$ are inferred for all incubations from tent interior $\mathrm{S}$ and T. (3) Time series of ambient concentrations of $\mathrm{C}_{T}, \mathrm{~A}_{\mathrm{T}}$ and $\mathrm{O}_{2}$ are predicted from linear relationships with salinity. (4) We calculate, accounting for leakage at a known and assumed constant rate, the time rate of substance input into the tent interior that best reproduce the observations made inside the enclosure. (5) We apportion the input of $\mathrm{C}_{\mathrm{T}}$ and $\mathrm{A}_{\mathrm{T}}$ into the contributions by the processes of $\mathrm{CaCO}_{3}$ dissolution and respiration. Lastly (6), all substance input rates are converted to fluxes.

\section{(1) Rate of water exchange}

The rate of water exchange across the enclosure $f$ (in units of $\min ^{-1}$ ) was estimated from the dampened response of measured in-tent salinity (S) to the variability of measured ambient (i.e. outside the tent) salinity over the duration of an incubation. This was performed by iterative minimization (based on least squares) of the residuals $q$ in equation 1.

$$
\mathrm{S}_{\mathrm{in}}{ }^{\mathrm{calc}}{ }_{\mathrm{t}+1}+\mathrm{q}=\left((1-\mathrm{f}) \cdot \mathrm{S}_{\mathrm{in}}{ }^{{ }^{\mathrm{calc}}}{ }_{\mathrm{t}}+\mathrm{f} \bullet \mathrm{S}_{\text {ambient }}{ }_{\mathrm{t}}{ }_{\mathrm{t}}\right)-\mathrm{S}_{\text {in }}{ }^{\text {meas }}
$$

where, $\mathrm{S}_{\mathrm{in}}{ }^{\text {calc }}{ }_{\mathrm{t}+1}$ is the calculated salinity inside the tent at time $t+1, \mathrm{~S}_{\mathrm{in}}{ }^{\text {calc }}$ the calculated salinity inside the tent at time $t$ and $\mathrm{S}_{\text {ambient }}{ }^{\text {meas }}$ the measured salinity outside the tent at time $t$.

\section{(2) Ambient hydrography}

With the estimated leak rate estimate $f$, an approximation of ambient salinity $S_{\text {ambient }}{ }^{\text {calc }}$ may be obtained from $\mathrm{S}_{\mathrm{in}}$ meas, which is available for all 5 incubations.

\section{(3) Ambient chemistry}

In order to know, at high temporal resolution, the concentrations of $\mathrm{O}_{2}, \mathrm{C}_{\mathrm{T}}$ and $\mathrm{T}_{\mathrm{A}}$ outside the enclosure, we regress measurements of these parameters against $S_{\text {ambientcalc. We }}$ use data collected (i) locally at the enclosure, supplemented by data obtained (i) by vertical profiling down to $\sim 75 \mathrm{~m}$ in the vicinity of the incubator and (ii) during expedition PE414 of the Dutch RV Pelagia in Aug/Sep 2016 close to Saba (hydrographic station \#49, $<5 \mathrm{~km}$ from enclosure location; De Nooijer and Van Heuven 2017). The use of data collected nearly a year later might be considered inappropriate. However, comparison between (i) Pelagia and (ii) tent ambient $\mathrm{A}_{\mathrm{T}}$ and $\mathrm{C}_{\mathrm{T}}$ data (and near tent profiles) is rather favourable.

\section{(4) Time rate of substance input $R$}

Having inferred (i) the (assumed constant) rate of exchange of water between tent and environment and (ii) the time history of ambient concentrations $\mathrm{C}_{\text {out }}$ of the parameter of interest (i.e., $\mathrm{A}_{\mathrm{T}}, \mathrm{C}_{\mathrm{T}}$, etc.) next we subsequently determined the constant time rate of substance input $R$ (in $\mu \mathrm{mol} \mathrm{kg}^{-1} \mathrm{hr}^{-1}$ ) that best explains the observed changes of concentration $C_{\text {in }}$ inside the enclosure while accounting for constant exchange with the environment. This is performed through iterative minimization of the residuals $q$ in Equation (2). 


$$
\mathrm{C}_{\text {in }}{ }^{\mathrm{t}}+\mathrm{q}=\mathrm{C}_{\text {in }}{ }^{\mathrm{t}-1} \cdot(1-\mathrm{f})+\mathrm{C}_{\text {ambient }}{ }^{\mathrm{t}-1} \bullet \mathrm{f}+\mathrm{R}
$$

The inferred input rate $\mathrm{R}$ is somewhat sensitive to the choice of the initial interior concentration $\left(\mathrm{C}_{\mathrm{in}}^{\mathrm{t}}{ }^{\mathrm{t}}\right)$. Using the measurement collected at the start of the incubation may affect the result due to stochastic measurement error. Therefore we used an initial $\mathrm{C}_{\text {in }}$ through careful observation of initial measurements performed in the enclosure and of the measured (and predicted) ambient conditions. The dictated initial interior concentrations were identical for all 5 incubations, supported by the observation of comparable ambient salinity at the start of each incubation.

An estimate of the robustness of the input rates of $\mathrm{O}_{2}, \mathrm{C}_{\mathrm{T}}$ and $\mathrm{A}_{\mathrm{T}}$ is obtained using a Monte Carlo approach (Figure S1). A thousand curve fits were performed as above, but after randomly perturbing (i) each of the measured values of $C_{T}$ and $A_{T}$ (both by samples from a normal distribution of width's' of $4 \mu \mathrm{mol} \mathrm{kg}^{-1}$, representing the measurement precision), (ii) the times of collection of the samples ( $\mathrm{s}=5$ minutes) and the leak rate of the tent $\left(\mathrm{s}=0.1 \% \mathrm{~min}^{-1}\right)$. If the standard deviation of the 1000 obtained input rates was smaller than the calculated nominal input rate, this nominal rate is considered to be significantly different from zero.

\section{(5) $\mathrm{CaCO}_{3}$ dissolution and respiration rates}

As outlined above, measurements of $\mathrm{A}_{\mathrm{T}}$ haven been adjusted for the effect of nutrient release by respiration. Subsequently, the individual contributions of $\mathrm{CaCO}_{3}$ dissolution and respiration to the observed concentrations (or fluxes) of $\mathrm{A}_{\mathrm{T}}$ and $\mathrm{C}_{\mathrm{T}}$ were calculated:

$$
\begin{aligned}
& \Delta \mathrm{A}_{\mathrm{T}}{ }^{\text {diss }}=\Delta \mathrm{A}_{\mathrm{T}}{ }^{\text {obsNC }} \\
& \Delta \mathrm{A}_{\mathrm{T}}^{\text {resp }}=0 \\
& \Delta \mathrm{C}_{\mathrm{T}}{ }^{\text {diss }}=\Delta \mathrm{A}_{\mathrm{T}}{ }^{\text {obsNC }} / 2 \\
& \left.\Delta \mathrm{C}_{\mathrm{T}}{ }^{\text {resp }}=\Delta \mathrm{C}_{\mathrm{T}}{ }^{\text {obs }}-\Delta \mathrm{C}_{\mathrm{T}}{ }^{\text {diss }}\right)
\end{aligned}
$$

change in $\mathrm{A}_{\mathrm{T}}$ due to dissolution change in $\mathrm{A}_{\mathrm{T}}$ due to respiration change in $\mathrm{C}_{\mathrm{T}}$ due to dissolution change in $\mathrm{C}_{\mathrm{T}}$ due to respiration

\section{(6) Conversion to fluxes}

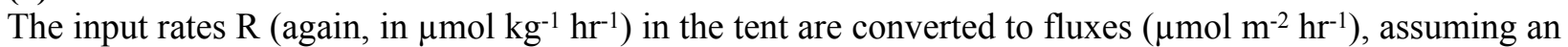
enclosed mass of water of $3000 \pm 150 \mathrm{~kg}$ (approximately 3200 litres enclosed; substrate volume is $\sim 250 \mathrm{~L}$; seawater density $\sim 1022 \mathrm{~kg} \mathrm{~m}^{-3}$ ) and an incubated planar surface of $4.4 \mathrm{~m}^{2}$.

Lastly, we compare our results with NCC estimates based on observed community composition and data published for the fluxes of various classes and species of reef organisms, following the ReefBudget approach of Perry et al. (2008). To measure the species specific cover within the incubated area, we took multiple photos from different angles and then used Image J v1.51j8 to quantify the precise cover of each functional benthic group. Rugosity was measured from 4 crossed transects through the incubated patch (see supplementary Table S1, S2 and S3).

\section{Results}

Application of Equation (1) to data collected during incubations 4 and 5 yields a leak rate of the enclosure f of $\sim 0.007 \mathrm{~min}^{-1}$. This indicates that $\sim 25 \mathrm{~kg}$ of seawater (i.e., $0.007 * 3000 \mathrm{~kg}$ ) is exchanged every minute between the incubation enclosure and the environment. Although $f \sim 0.007$ accurately relates interior and ambient salinity observations made during incubations 4 and 5, we have no direct means of ascertaining that it also applies to preceding incubations. However, given the sparse ambient salinity data, we assume this water exchange rate to be constant throughout all incubations. Because the sealing of the tent to the substrate remained unchanged from the second incubation onwards, the time history of ambient salinity $\mathrm{S}_{\text {out }}{ }^{\text {calc }}$ was derived under the assumption of $\mathrm{f}$ being $\sim 0.007$. During incubations the error between $\mathrm{S}_{\text {out }}{ }^{\text {meas }}$ and $\mathrm{S}_{\text {out }}{ }^{\text {calc }}$ was $-0.023 \pm 0.19$ (range: 34.7-36.0). The good match indicates validity of this simple adjective exchange model.

The ambient hydrographic conditions reflect variable admixture of a deeper, colder and more saline component into the warmer, and fresher waterbody that is more commonly encountered at the incubation 
site (see Figure 3a). In these ambient waters, $\mathrm{C}_{\mathrm{T}}$ and $\mathrm{A}_{\mathrm{T}}$ increase with $\mathrm{S}$ as is expected. Oxygen, too, is observed to increase with increasing $\mathrm{S}$, due to the higher solubility in the more saline and - crucially - colder water. Regressions between $\mathrm{S}$ and $\mathrm{O}_{2} / \mathrm{C}_{\mathrm{T}} / \mathrm{A}_{\mathrm{T}}$ are presented in Figure 3, panels b, $\mathrm{d}$ and $\mathrm{f}$. The time histories of these properties, derived using $\mathrm{S}_{\text {ambient }}{ }^{\text {calc }}$, are presented in Figure 3, panels c, e and g. For nutrients, no regressions were performed since ambient concentrations were essentially invariant at zero compared to the in-tent changes during incubations (Figure S2).

Figure 3. (a) Salinity and temperature recorded outside the enclosure show occasional mixing of a cool, saline deep water body into the warmer, fresher surface water component that is most commonly observed at the depth of the enclosure (as indicated by the high density of data points at S 34.8). (b, d, f) Regression against salinity of, respectively, $\mathrm{A}_{\mathrm{T}}, \mathrm{C}_{\mathrm{T}}$ and $\mathrm{O}_{2}$. Samples in these regressions originate from three sources (two for $\mathrm{O}_{2}$ ). (c, e, g) Measured values of, respectively $\mathrm{A}_{\mathrm{T}}, \mathrm{C}_{\mathrm{T}}$ and $\mathrm{O}_{2}$, plotted together with time trace of these values, generated from the regressions against salinity.

Figure 4 illustrates the results of our approach for incubation 4. For an overview of all results from all incubations, please refer to supplementary Table S4 and/or Figure S3. The model employed fits the measurements for $C_{T}$ and $A_{T}$ relatively well: the rmse of the fit of $C_{T}$ is $3.5 \mu \mathrm{mol} \mathrm{kg-1} \mathrm{-} \mathrm{identical} \mathrm{to} \mathrm{the}$ measurement uncertainty of $\mathrm{C}_{\mathrm{T}}$ itself. For $\mathrm{A}_{\mathrm{T}}$ the fit $(5.3 \mu \mathrm{mol} / \mathrm{kg})$ is slightly worse than instrument precision $(3.5 \mu \mathrm{mol} \mathrm{kg-1)}$.

Figure 4. Illustrative results of the model (bold red line) employed to infer the substance input rates from observations, here for incubation 4. (a) A water exchange rate of $0.007 \mathrm{~min}^{-1}$ between enclosure and environment optimally relates ambient and interior measurements of salinity. Back-calculating ambient salinity from interior salinity is shown here to be feasible. (b) Ambient temperature co-varies with S. From T, the exchange rate is inferred to be 0.012 min- 1 (higher than from $\mathrm{S}$ due to additional conductive equilibration). Additionally, in (c-f), we present results of a simplistic asymptotic curve fitting (thin red line) to show how the two methods may diverge appreciably, here mostly evidently for $\mathrm{A}_{\mathrm{T}}$. (Note that the uncertainty of the asymptotic fit is worse than that of the model used in this study).

For the five incubations, consumption of oxygen from the incubated seawater ranged from -10 to $-30 \mu \mathrm{mol}$ $\mathrm{kgSW}^{-1}$ hour-1 (Table S4). Concomitant increase of $\mathrm{C}_{\mathrm{T}}, \mathrm{PO}_{4}$ and $\mathrm{NO}_{2+3}$ strongly suggests respiration to be the dominant process throughout these incubations. Respiration should decrease $\mathrm{A}_{\mathrm{T}}$ slightly due to the release of nutrients, but an even larger decrease is inferred by the full model suggesting a significant role for net calcification during incubation 2, 3 and 4. For the incubation 1 and 5 on the other hand, slight $\mathrm{CaCO}_{3}$ dissolution is inferred. Prior to inferring rates, values of $\mathrm{A}_{\mathrm{T}}$ were adjusted to account for the release of nutrients during respiration according to equation (3). Therefore, by definition the respiration $\mathrm{A}_{\mathrm{T}}$ rate is zero for all incubations (Table 2).

Results obtained from incubations using the smaller, secondary tent suggests at most a very limited role for sedimentary processes (see Supplementary Figure S4): although exterior concentrations of $A_{T}$ and $C_{T}$ increased by as much as $60 \mu \mathrm{mol} \mathrm{kg}{ }^{-1}$ in the $2 \mathrm{nd}$ half of the incubation, interior $\mathrm{A}_{\mathrm{T}}$ and $\mathrm{C}_{\mathrm{T}}$ during those 4 hours did not increase at rates higher than $2.5 \mu \mathrm{mol} \mathrm{kg} \mathrm{hr}^{-1}$. This limited response suggests a leak rate between 0.2 and $1 \% \mathrm{~min}^{-1}$. Appreciable accumulation may therefore be expected if fluxes are present, also because of the small tent's favorable volume-to-surface ratio $\left(2751 \mathrm{~m}^{-2}\right.$, vs $7501 \mathrm{~m}^{-2}$ for the dome tent). Over the first 165 minutes of the incubation, however, interior $\mathrm{A}_{\mathrm{T}}$ and $\mathrm{C}_{\mathrm{T}}$ increase only by 1 and $2 \mu \mathrm{mol}$ $\mathrm{kg}^{-1}$ compared to initial conditions (commensurate flux: $\sim 0.3$ and $0.6 \mathrm{mmol} \mathrm{m}^{-2} \mathrm{hr}^{-1}$, i.e, one or two orders of magnitude lower than in the main tent; note that appreciable errors apply both to measurements and conversion to flux). These increases may be linked to exchange with ambient waters. No changes in pyramid tent nutrient concentrations were observed, suggesting low rates of productivity or respiratory processes. For subsequent calculations, we consider the contribution by sedimentary processes to be negligible.

Subsequently, the concentration changes in oxygen, inorganic carbon, etc. in the dome-tent were used to calculate the fluxes during each of the five main incubations (Table 2). No trends were observed in TOC concentrations within the tent during incubations, despite clear trends being observed for $\mathrm{C}_{\mathrm{T}}$. 
Table 2. Summary of fluxes inferred from observed concentration changes in the enclosure during each of five incubation periods. Non-significant fluxes are greyed out. See text for methods for derivation of rates and uncertainties. All fluxes in mmol hour ${ }^{-1} \mathrm{~m}^{-2}$ (planar incubated surface area). Negative dissolution fluxes are described (instead of positive calcification) to maintain co-directionality of the fluxes of respiration and dissolution.

Table 3. NCC of the planar total area inside the incubation calculated from fluxes and the ReefBuget method.

Deviations of the tent leak rate from the nominal $0.7 \% \mathrm{~min}^{-1}$ (or 'breach events') are observed during all incubations. These deviations from our assumption may negatively affect the inferred rates of change in $\mathrm{O}_{2}$ concentrations, as evident from the differing slopes of trace and fit near the starts of incubations. Considering only the first 30 minutes of the oxygen traces (preceding tentative breach events in all incubations), appreciably higher oxygen consumption is inferred than when considering the full traces (Table S5). At constant ambient $\mathrm{S}, \mathrm{O}_{2}, \mathrm{C}_{\mathrm{T}}$ and $\mathrm{A}_{\mathrm{T}}$, leakage at a rate higher than the $0.7 \% \mathrm{~min}^{-1}$ that we assume would result in underestimation of the true fluxes of $\mathrm{O}_{2}, \mathrm{C}_{\mathrm{T}}$ and $\mathrm{A}_{\mathrm{T}}$. No change would be observed in the O-flux/C-flux ratio that we infer. Conversely, at times of sudden high ambient $\mathrm{S}, \mathrm{O}_{2}, \mathrm{C}_{\mathrm{T}}$ and $\mathrm{A}_{\mathrm{T}}$, leakage at a rate higher than the $0.7 \% \mathrm{~min}^{-1}$ that we assume would result in overestimation of $\mathrm{C}_{\mathrm{T}}$ and $\mathrm{A}_{\mathrm{T}}$ fluxes, and underestimation of $\mathrm{O}_{2}$ fluxes. This would change the $\mathrm{O}$-flux/C-flux ratio that we infer. However, as we do not know if the $\mathrm{O}_{2}$ trace is asymptotic, or that the tent did indeed leak at higher or lower rates than $0.7 \% \mathrm{~min}^{-1}$, results are likely still valid (i.e., when no breach events occurred, and $\mathrm{O}_{2}$ deviations resulted from sensor artefacts or true biological activity). We therefore maintained the conceivably affected incubations in the paper.

The NCC inferred from our incubations ranges from $-0.5 \mathrm{~kg} \mathrm{CaCO}_{3} \mathrm{~m}^{-2} \mathrm{yr}^{-1}$ to $2.8 \mathrm{~kg} \mathrm{CaCO}_{3} \mathrm{~m}^{-2} \mathrm{yr}^{-1}$ which is on average higher but still in range than the $\mathrm{NCC}$ estimated from the ReefBudget method $(0.36 \mathrm{~kg} \mathrm{CaCO} 3$ $\mathrm{m}^{-2} \mathrm{yr}^{-1}$, Table 3).

Table 4: Stoichiometry of rates observed during 5 incubations. Values in column "avg." are calculated as the ratio of the sums of incubations 2-5. Uncertainties are calculated by error propagation. Rightmost two columns show literature values from (i) Redfield et al (1963) and (ii) Atkinson and Smith (1983), representing the elemental compositions of (i) marine phytoplankton and (ii) benthic macroalgae. Our incubation results most closely resemble the latter.

Our results indicate that the tent incubation is an effective tool for in-situ quantification of reef fluxes in reef-overlaying water. Quantification of fluxes was achieved despite strong variability in ambient conditions and in the presence of appreciable swell induced seawater exchange. To this end we applied a comprehensive conceptual framework for the interpretation of the measured concentration differences. This method allows for a volume exchange between the environment and the incubation thereby replenishing the latter and keeping the $\mathrm{O}_{2}$ levels within the tent near ambient conditions resulting in minimised unrepresentative reef community metabolism. By continuously monitoring the inside environment and assuming constant exchange rate, fluxes within our incubation can be treated as if acquired by a flow through system. Nonetheless, future application of this or similar incubation methods could be further improved by continuous monitoring of the exchange rate, rather than assuming it to be constant throughout the incubation. This could be obtained for instance by running a second thermosalinograph outside the tent. The application of a conceptually simpler 'asymptotic' model yields different and less well-constrained results. Particularly, the direction of the $\mathrm{CaCO}_{3}$ dissolution flux may be seen to be reversed in the simpler method (see also Figure 4). In all incubations, for both $\mathrm{A}_{\mathrm{T}}$ and $\mathrm{C}_{\mathrm{T}}$, the uncertainty in measured concentration differences and the variability between results may be greater for the simpler model (Supplementary Table $\mathrm{S} 4$; supplementary Figure $\mathrm{S} 3$ ). In the case of $\mathrm{A}_{\mathrm{T}}$ (Figure $4 \mathrm{f}$ ), the assumed-to-be-constant input of $\mathrm{A}_{\mathrm{T}}$ inferred by the model applied here is of opposite sign to the simpler asymptotic model result $\left(-0.6 \mathrm{vs}+7.1 \mu \mathrm{mol} \mathrm{\textrm {kg } ^ { - 1 }}\right.$ $\mathrm{hr}^{-1}$ ). This reversal of sign of the $\mathrm{A}_{\mathrm{T}}$ rates observed between the two models (asymptotic and full) is caused by the inability of the asymptotic model to account for occasional intrusion of high- $\mathrm{A}_{\mathrm{T}}$ ambient water into 
408

409

410

411

412

413

414

415

416

417

418

419

420

421

422

423

424

425

426

427

428

429

430

431

432

433

434

435

436

437

438

439

440

441

442

443

444

445

446

447

448

449

450

451

452

453

454

455

456

457

458 the tent during sudden changes in ambient hydrography. The asymptotic model (panels c \& d) shows a relatively good fit of the observations of $\mathrm{O}_{2}$ and $\mathrm{NO}_{2+3}$ around the fitted curve, which is due to the invariant ambient concentrations of these parameters.

In contrast with previous studies carried out at shallower depths using either Lagrangian drifts or incubations, all net diurnal rates from this study are strongly skewed towards respiration suggesting net heterotrophy in all incubations. Studies performed at shallower depths shift between net autrotophy and net heterotrophy over the course of a day (Yates et al., 2003, Albright, Langdon and Anthony, 2013; 2015). However, previously reported average net respiration rates occurring at night on shallower reefs are comparable to results from this study (14.5 to $\left.35.5 \mathrm{mmol} \mathrm{C} \mathrm{m}^{-2} \mathrm{~h}^{-1}\right)$. Results are also comparable to previously reported values at depth. For example, Middelburg, Duarte and Gattuso (2005) compiled a global mean coral reef respiration rate of $131 \pm 46 \mathrm{~mol} \mathrm{C} \mathrm{m}^{-2} \mathrm{yr}^{-1}$. Specifically for their categories 'outer reef slopes' and 'high activity areas' they report values of $140 \pm 70$ and $413 \pm 187 \mathrm{~mol} \mathrm{C} \mathrm{m}^{-2} \mathrm{yr}^{-1}$, respectively. This range compares well to the rates reported here (105-298 mol C m$~_{-2} \mathrm{yr}^{-1}$ for the full planar surface). A stoichiometric comparison of the inferred fluxes of $\mathrm{C}_{\mathrm{T}}$, oxygen and nutrients is combined with (i) the canonical 'Redfield ratio' (Redfield et al., 1963) of the elemental composition of open ocean phytoplankton and (ii) the median elemental composition of benthic macroalga (Atkinson and Smith, 1983), likely resembling the composition of the labile fraction of the locally present organic carbon (Table 4).. This shows that the community incubated in this experiment respires carbon and nutrients in a ratio that resembles the composition of benthic macroalgae (Atkinson and Smith, 1983) which indicates that the observed signal is indeed originating from the sedimentary, benthic, macrofaunal, and/or bacterial constituents of the enclosed community.

A strong correlation between NCC and net community productivity in reef environments is well documented (Gattuso et al., 1996; Shaw, McNeil and Tilbrook, 2012, Shaw et al., 2015; McMahon et al., 2013; Albright et al., 2015) however, no correlation was found in our incubations. The NCC inferred from our incubations ranged from -0.5 to $2.8 \mathrm{~kg} \mathrm{CaCO}_{3} \mathrm{~m}^{-2} \mathrm{yr}^{-1}$ which is on average higher than the mean recorded rate of $0.2 \mathrm{~kg} \mathrm{CaCO}_{3} \mathrm{~m}^{-2} \mathrm{yr}^{-1}$ associated with a Floridian reef patch ( $10 \%$ coral cover $)$ in shallower waters (Yates, 2003) using a similar method.

Applying the ReefBudget approach to our benthic census data for comparison, we obtain a NCC for the full incubated substrate surface (i.e., sand and hard substrate) of $\sim 0.36 \mathrm{~kg} \mathrm{CaCO}_{3} \mathrm{~m}^{-2} \mathrm{yr}^{-1}$ (see Table 3). This estimate is lower (but still within error) than the average NCC inferred from our incubations $(\sim 0.88 \pm 1 \mathrm{~kg}$ $\mathrm{CaCO} 3 \mathrm{~m}-2 \mathrm{yr}-1$, Table 3 ). The range of NCC estimates inferred from our results indicates how sensitive metabolic and chemical processes on coral reefs are to their environment. The chemical flux-based method as presented here is appreciably sensitive to the effects of the surrounding hydrological conditions on the substrate and this may be the source for a slight discrepancy compared to the ReefBudget approach. NCC rates acquired by Perry et al. (2013) associated with a coral cover ranging between $4-5 \%$ and at similar depth (17-20 meters) in the Bahamas are all negative (ranging from $-0.01 \mathrm{~kg} \mathrm{CaCO}_{3} \mathrm{~m}^{-2} \mathrm{yr}^{-1}$ to $-0.23 \mathrm{~kg}$ $\left.\mathrm{CaCO}_{3} \mathrm{~m}^{-2} \mathrm{yr}^{-1}\right)$. This may be explained by varying community composition such as the absence of macrobioeroders within our tent. Furthermore, the flux-based method does not assess the mechanical component of bioerosion (caused by parrot fish or sponges for instance) which is important to the process of reef accretion.

The ReefBudget method offers a fast and convenient tool for estimating reef biogenic carbonate production states both on a remarkable temporal and spatial scale. Although the incubated flux-based approach, may be more sensitive to unstable and varying reef states, it cannot offer such a large spectrum of study. However, it provides an assessment of the full community without having to determine calcification/dissolution rates as a function of surface area. This can be very useful to assess the effect of endolithic species or determine the impact that some understudied organism may have on the chemical conditions. For instance, benthic cyanobacterial mats have been shown to proliferate around the islands of Curacao and Bonaire since 2003 (De Bakker et al. 2017) and are described to effect $\mathrm{pH}$ on a local scale (Hallock et al., 2005; Paerl et al., 2012). However, close to no records on how these mats may alter reef chemical conditions and subsequently impact the calcifying/bioeroding community are available.

PeerJ reviewing PDF | (2018:01:23723:3:2:NEW 18 Oct 2018) 
459 Currently, the ReefBudget approach relies on various assumptions regarding the calculation of each 460 biological component. As such, the flux-based approach described here should not be regarded as a 461 substitute for survey methods such as the ReefBudget, but rather as a complementary tool. Using the fluxbased approach, it will become easier to determine missing components and variations in chemical dissolution/calcification on a spatial (e.g. depth) and also smaller temporal scale (i.e. diurnal cycle, seasonality), therewith improving survey based carbonate budget assessments.

To determine if the respiration signal might be an artefact of the incubation treatment, we identify potential causes that may perturb the signal. The estimated contribution by macrofauna such as fish, crustaceans and nudibranchs to the observed respiration signal is deemed to be negligible: considering a fish mass-specific $\mathrm{O}_{2}$ consumption rate of $\sim 100 \mathrm{mgO}_{2} \mathrm{~h}^{-1} \mathrm{~kg}^{-1}$ (Roche et al., 2013), and assuming 100 grams of fish to be present in the tent (which is likely a strong overestimate as only very few small fish were observed during incubations), we calculate a contribution to $\mathrm{C}_{\mathrm{T}}$ in the incubation of $\sim 0.1 \mu \mathrm{mol} \mathrm{kg}{ }^{-1} \mathrm{~h}^{-1}$, which is two orders of magnitude smaller than the observed respiration rates of $10-30 \mu \mathrm{mol} \mathrm{kg}^{-1}$. Additionally, we rule out that 'free floating' TOC (e.g., coral exudates) is the material that is respired. While clear fluxes are inferred for $\mathrm{C}_{\mathrm{T}}$, no trends were observed in TOC concentrations within the tent during incubations. Alternatively, no significant depression was observed of average interior TOC values $\left(84 \pm 9 \mu \mathrm{mol} \mathrm{kg}^{-1}, \mathrm{n}=39\right)$ relative to exterior TOC $\left(86 \pm 7 \mu \mathrm{mol} \mathrm{kg}^{-1}, \mathrm{n}=8\right)$. Although the tentative drop in TOC resembles the small drop observed in dedicated DOC depletion experiments (e.g., De Goeij and Van Duyl, 2007), the lack of volume flow through the tent means TOC cannot be more than a very minor source of respirable carbon. Absence of depletion of suspended labile TOC notwithstanding, TOC may still play a role in the form of mucus if that is adhered to substrate or incubator, out of reach of sampling but available for bacterial respiration. However, the respiring biomass required for the observed $\mathrm{C}_{\mathrm{T}}$ increases is unlikely to be present in the form of bacteria, especially shortly after incubation start. Indeed, Wild et al. (2004) show from small-scale incubations that the bacterial degradation of coral mucus, introduced into their incubators (containing only sediment and water column) at high concentrations, occurs at rates of $0.7-2.1 \mathrm{mmol} \mathrm{m}^{-2} \mathrm{hr}^{-1}$. That compares to rates around $60-175 \mathrm{mmol} \mathrm{m} \mathrm{m}^{-2} \mathrm{hr}^{-1}$ observed in our experiment, suggesting remineralization of adhered mucus plays at best a minor role in our incubations, further suggesting the observed fluxes to originate from the macroscopic biotic substrate.

In that category, sponges are the most likely organisms respiring, having appreciable biomass and containing ample energy stores to maintain respiration during the incubation periods, in which only limited amounts of organic carbon are available for filter feeding. Hadas et al. (2008) report (Red Sea) sponge basal oxygen consumption to be $\sim 50 \%$ of consumption featured during full water pumping activity, which means that sponge respiration largely continues even when filter feeding ceases. These authors report a rate of 2.4 $\mu \mathrm{mol} \mathrm{O} \mathrm{hr}^{-1} \mathrm{~g}^{-1}$ (wet weight). Similarly, Ludemann, Reidenbach and Leys (2017) report sponge oxygen consumption (standardized to sponge volume) ranging from $0.3-3 \mu \mathrm{mol} \mathrm{h}^{-1} \mathrm{ml}^{-1}$, with strong species dependence. Assuming the higher end of this range applies to the sponges incubated in our experiment (mostly Agelas sp., Callyspongia plicifera), and assuming as much as $5 \mathrm{~kg}$ wet weight of sponge to have been present in the enclosure, we account for $\sim 5 \mu \mathrm{mol} \mathrm{kg}{ }^{-1} \mathrm{hr}^{-1}$ of the observed rates of $\sim 30 \mu \mathrm{mol} \mathrm{kg}^{-1} \mathrm{hr}^{-1}$. Maintained respiration by sponges throughout the series of incubations could be fuelled by filter feeding during the $\sim 50 \%$ of the time in which the incubator was open to the ambient water. Recent research by McMurray et al. (2018) showed that species hosting abundant symbiotic microbes (i.e. high microbial abundance or HMA) primarily consumed dissolved organic carbon (DOC), while the diet of species with low microbial abundances (LMA) primarily consisted of detritus and picoplankton. They further pointed out that it remained unknown if DOC released by LMA species could be a source of food for HMA species. The main sponges incubated in our experiment are Agelas sp. and Callyspongia plicifera and represent respectively a HMA and a LMA sponge. We tentatively infer that this may explain partly the observed high respiration rate. Nevertheless, we cannot infer if sponges are able to maintain metabolic balance throughout the incubation period, or that they deplete their stores. Further analyses such as bacterial counts would be needed to answer such questions. From Table 2 we conclude oxygen consumption rate during daytime 
510 (incubations 2 and 4) to be lower by $\sim 5 \mu \mathrm{mol} \mathrm{kg}{ }^{-1} \mathrm{hr}^{-1}$ than night time rates (incubations 3 and 5), hinting

511 at a role of primary producers (corals, $\mathrm{CCA}$, macro and microalgae).

512

513 The lack of accumulation of $\mathrm{C}_{\mathrm{T}}$ in the secondary, small incubation places our sediment at the very low end of literature values regarding respiration. For example, Middelburg, Duarte and Gattuso (2005) report a global mean sediment respiration value of $\sim 8.5 \pm 7 \mathrm{mmol} \mathrm{C} \mathrm{m}^{-2} \mathrm{~h}^{-1}$ (as approximated from their Figure 11.3). Our observed low values may be reasonable considering the highly hydrodynamic nature of the incubation environment which likely hampers settlement of substantial amounts of organic matter onto and into the sediment. In addition, the volcanic sandy composition of the sediment around Saba may be less prone to dissolution than coralline sediment and could explain the insignificant increase in $\mathrm{A}_{\mathrm{T}}$ in the small tent. However, Eyre et al. (2018) shows similar results for sediment around Cook Islands which is mostly composed of calcareous fragments (Wood, 1967). Eyre et al. (2018) shows that dissolution in reef sediment across different locations around the world is negatively correlated with the aragonite saturation state $\left(\Omega_{\mathrm{ar}}\right)$. Average $\Omega_{\mathrm{ar}}$ of ambient water around the tent incubation throughout the experiment is calculated to be 3.85 which is more comparable to islands (Bermuda and Tetiaroa) showing accretion in reef sediment. The combined effects of hydrodynamics and sand composition are likely to explain why our results present neither accretion nor dissolution in our tent's sediment.

526

\section{Conclusions}

528 Flux-based carbonate budget studies, as presented here, provide quantitative data on the functional state of 529 reefs in terms of biologically driven carbonate production which is particularly sensitive to ambient environmental conditions. As such, they can be particularly useful for temporal studies, especially to reveal not only diurnal and seasonal patterns but also to capture shifts in functionality of reef systems. We incubated a coral reef patch situated in a high-energy environment which caused a limited amount of seawater exchange. Monitoring of conditions within and outside the tent allowed for determination of the exchange rate and thereby allowed for correcting the respiration and calcification rates. Application of this procedure shows that this reef patch is characterized by NCC inside the tent at a rate within range but on average higher than fluxes reported in previous studies for shallower reef systems indicating coherence in our results. However, the range of NCC estimates inferred from our results accounts for the sensitivity of this reef patch to the surrounding environment. Furthermore, the net heterotrophy reported here both during the day and the night differs from studies performed at shallower depths where shifts between net autotrophy and net heterotrophy are observed. Future research may include various types of substrates and comparison between regions with varying water quality.

542

\section{3}

544

545

546

547

\section{Acknowledgements}

The authors are particularly grateful to the captain and crew of Caribbean Explorer II, who have been outstandingly helpful and accommodating. We also would like to thank the institutional support of Saba Marine Parks, Caribbean Netherlands Science Institute (CNSI) and Wageningen Marine Research (WMR). Additional gratitude is reserved for Janine Nauw, Johan Stapel, Steve Piontek, and volunteer divers Oscar 548 
549

550

551

552

553

554

555

556

557

558

559

560

561

562

563

564

565

566

567

568

569

570

571

572

573

574

575

576

577

578

579

580

581

582

583

584

585

586

587

588

589

590

591

592

593

594

595

596

597

598

599

600

601

602

603

\section{References:}

Albright, R., Langdon, C., \& Anthony, K. R. N. (2013). Dynamics of seawater carbonate chemistry, production, and calcification of a coral reef flat, central Great Barrier Reef. Biogeosciences, 10(10), 6747-6758.

Albright, R., Benthuysen, J., Cantin, N., Caldeira, K., \& Anthony, K. (2015). Coral reef metabolism and carbon chemistry dynamics of a coral reef flat. Geophysical Research Letters, 42(10), 3980-3988.

Albright, R., Caldeira, L., Hosfelt, J., Kwiatkowski, L., Maclaren, J. K., Mason, B. M., Nebuchina, Y., Ninokawa,, A., Pongratz, J., Ricke, K., Rivlin, T., Schneider, K., Sesboüé, M., Shamberger, K., Silverman, J., Wolfe, K., Zhu, K., Caldeira, K. (2016). Reversal of ocean acidification enhances net coral reef calcification. Nature, 115. http://doi.org/10.1038/nature 17155

Alevizon, W.S., J.W. Porter (2015), Coral loss and fish guild stability on a Caribbean coral reef: 1974-2000. Environmental Biology of Fishes 98, 1035-1045.

Alvarez-Filip L, Dulvy NK, Côté IM, Watkinson AR, Gill JA (2011a). Coral identity underpins architectural complexity on Caribbean reefs. Ecol Appl 21:2223-2231

Andersson, A. J., \& Gledhill, D. (2013). Ocean acidification and coral reefs: effects on breakdown, dissolution, and net ecosystem calcification. Annual Review of Marine Science, 5, 321-348.

Anthony, K.R.N., D.I. Kline, G. Diaz-Pulido, S. Dove, O. Hoegh-Guldberg (2008), Ocean acidification causes bleaching and productivity loss in coral reef builders, Proceedings of the National Academy of Sciences of the United States of America 105(45), 17442-17446.

Aronson, R.B., and W.F. Precht (1997), Stasis, biological disturbance, and community structure of a Holocene coral reef, Paleobiology 23(3), 326-346.

Atkinson, M. J., \& Smith, S. V. (1983). C: N: P ratios of benthic marine plants1. Limnology and Oceanography, 28(3), 568-574.

Baker, A.C., Glynn, P.W., Riegl, B. (2008), Climate change and coral reef bleaching: An ecological assessment of long-term impacts, recovery trends and future outlook, Estuarine, Coastal and Shelf Science 80(4), $435-471$.

Burkepile, D.E., M.E. Hay (2009), Nutrient versus herbivore control of macroalgal community development and coral growth on a Caribbean reef, Marine Ecology Progress Series 389, 71-84.

Camp, E.F., S.-L. Krause, L.M.F. Santos, M.S. Naumann, R.K.P. Kikuchi, D.J. Smith, C. Wild, D.J. Suggett (2015), The "Flexi-Chamber": a novel cost-effective in situ respirometry chamber for coral physiological measurements. PLOS One 10(10), e0138800.

Carilli, J.E., R.D. Norris, B.A. Black, S.M. Walsh, M. McField (2009), Local stressors reduce coral resilience to bleaching, PLOS One 4(7), doi:10.1371/journal.pone.0006324.

Chaves-Fonnegra, A., Zea, S., \& Gómez, M. L. (2007). Abundance of the excavating sponge Cliona delitrix in relation to sewage discharge at San Andrés Island, SW Caribbean, Colombia. Boletın de Investigaciones Marinas y Costeras, 36, 63-78.

Chow, M.H., R.H.L. Tsang, E.K.Y. Lam, P. Ang (2016), Quantifying the degree of coral bleaching using digital photographic technique. Journal of Experimental Marine Biology and Ecology 479, 60-86.

Coles, S.L, and E.K. Brown (2007), Twenty-five years of change in coral coverage on a hurricane impacted reef in Hawai'i: The importance of recruitment, Coral Reefs 26(3), 705-171.

Courtney, T.A., A.J. Andersson, N.R. Bates, A. Collins, T. Cyronak, S.J. de Putron, B.D. Eyre, R. Garley, E.J. Hochberg, R. Johnson, S. Musielewicz, T.J. Noyes, C.L. Sabine, A.J. Sutton, J. Toncin, A. Tribollet (2016). Comparing chemistry and census-based estimates of net ecosystem calcification on a rim reef in Bermuda. Frontiers in Marine Science 3, 181.

Cyronak, T., Santos, I. R., McMahon, A., \& Eyre, B. D. (2012). Carbon cycling hysteresis in permeable carbonate sands over a diel cycle: Implications for ocean acidification. Limnology and Oceanography, 58(1), $131-143$. http://doi.org/10.4319/1o.2013.58.1.0131

De'ath, G., K.E. Fabricus, H. Sweatman, and M. Puotinen (2012), The 27-year decline of coral cover on the Great Barrier Reef and its causes. Proceedings of the National Academy of Sciences of the United States of America, 109 (44), 17995-17999.

De Bakker, D. M., Meesters, E. H., Bak, R. P. M., Nieuwland, G., \& van Duyl, F. C. (2016). Long-term Shifts in Coral Communities On Shallow to Deep Reef Slopes of Curaçao and Bonaire: Are There Any Winners? Frontiers in Marine Science, 3, e83829-14. http://doi.org/10.3389/fmars.2016.00247

De Bakker,D.M.,vanDuyl,F.C.,Bak,R.P.M.,Nugues,M.M.,Nieuwland,G.,and Meesters, E. H. (2017). 40 years of benthic community change on the Caribbean reefs of curaçao and bonaire: the rise of slimy cyanobacterial mats. Coral Reefs 36, 355-367. 
604

605

606

607

608

609

610

611

612

613

614

615

616

617

618

619

620

621

622

623

624

625

626

627

628

629

630

631

632

633

634

635

636

637

638

639

640

641

642

643

644

645

646

647

648

649

650

651

652

653

654

655

656

657

658

de Goeij, J. M., \& Van Duyl, F. C. (2007). Coral cavities are sinks of dissolved organic carbon (DOC). Limnology and Oceanography, 52(6), 2608-2617.

Dickson, A. G., \& Christian, J. (2007). Guide to best practices for ocean CO2 measurements. (PICES Special Publication 3, 191 Pp.).

Duckworth, A. R., \& Peterson, B. J. (2013). Effects of seawater temperature and pH on the boring rates of the sponge Cliona celata in scallop shells. Marine Biology, 160(1), 27-35.

Edinger, E.N., G.V. Limmon, J. Jompa, W. Widjatmoko, J. M. Heikoop, M.J. Risk (2000). Normal coral growth rates on dying reefs: Are coral growth rates good indicators of reef health? Marine Pollution Bulletin 40(5), 404425 .

Edinger EN, Risk MJ (2000). Reef classification by coral morphology predicts coral reef conservation value. Biol Conserv 92:1-13

Etnoyer, P.J., H.H. Wirshing, and J.A. Sanchez (2010), Rapid assessment of octocoral diversity and habitat on Saba Bank, Nehterlands Antilles. PLoS ONE 5, e10668.

Eyre, B.D., Cyronak, T., Drupp, P., De Carlo, E.H., Sachs, J.P., Andersson, A.J. (2018) Coral reefs will transition to net dissolving before end of century. Science. 23;359(6378):908-11.

Fang, J. K. H., Mello-Athayde, M. A., Schönberg, C. H. L., Kline, D. I., Hoegh-Guldberg, O., \& Dove, S. (2013). Sponge biomass and bioerosion rates increase under ocean warming and acidification. Global Change Biology, 19(12), 3581-3591. http://doi.org/10.1111/gcb.12334

Gardner, T.A., I.M. Cote, J.A. Gill, A. Grant, and A.R. Watkinson (2003), Long-term region-wide declines in Caribbean corals. Science, 301(5635), 958-960.

Gattuso, J.P., M. Pichon, B. Delesalle, and M. Frankignouille (1993), Community metabolism and air-sea CO2 fluxes in a coral-reef ecosystem (Moorea, French-Polynesia), Marine Ecology Progress Series 96(3), 259-267.

Gattuso, J.P., M. Pinchon, B. Delasalle, C. Canon, and M. Frankignouille (1996), Carbon fluxes in coral reefs. I. Langrangian measurement of community metabolism and resulting air-sea $\mathrm{CO} 2$ disequilibrium, Marine Ecology Progress Series 145, 109-121.

Gilmour, J. (1999), Experimental investigation into the effects of suspended sediment on fertilisation, larval survival and settlement in a scleractinian coral, Marine Biology 135(3): 451-462.

Graham, N. A. J., \& Nash, K. L. (2013). The importance of structural complexity in coral reef ecosystems. Coral Reefs, 32(2), 315-326.

Haas, A.F., Nelson, C.E., Rohwer, F., Wegley-Kelly, L., Quistad, S.D., Carlson, C.A., Leichter, J.J., Hatay, M. and Smith, J.E. (2013). Influence of coral and algal exudates on microbially mediated reef metabolism. PeerJ, 1, p.e108.

Hadas, E., Ilan, M., \& Shpigel, M. (2008). Oxygen consumption by a coral reef sponge. Journal of Experimental Biology, 211(13), 2185-2190.

Hallock, P. (2005). Global change and modern coral reefs: new opportunities to understand shallow-water carbonate depositional processes. Sedimentary Geology, 175(1-4), 19-33.

Hoegh-Guldberg, O. (1999), Climate change, coral bleaching and the future of the world's coral reefs, Marine and Freshwater Research, 50(8), 839-866.

Hoegh-Guldberg, O., P.J. Mumby, A.J. Hooten, R.S. Steneck, P. Greenfield, E. Gomez, C.D. Harvell, P.F. Sale, A.J. Edwards, K. Caldeira, N. Knowlton, C.M. Eakin, R. Iglesias-Prieto, N. Muthiga, R.H. Bradbury, A. Dubi, and M.E. Hatziolos (2007), Coral reefs under rapid climate change and ocean acidification, Science 318(5857), $1737-1742$.

Hubbard, D.K., Miller, A.I., Scaturo, D. (1990). Production and cycling of calcium carbonate in a shelf-edge reef system (St. Croix, US Virgin Islands): applications to the nature of reef systems in the fossil record. Journal of Sedimentary Research, 60(3).

Hughes, T.P. (1994), Catastrophes, phase-shifts, and large-scale degradation of a Caribbean coral reef, Science 265(5178), 1547-1551.

Hughes, T.P., M.J. Rodrigues, D.R. Bellwood, D. Ceccarelli, O. Hoegh-Guldberg, L. McCook, N. Moltschwaniwskyj, M.S. Pratchett, R.S. Steneck, and B. Willis (2007), Phase shifts, herbivory, and the resilience of coral reefs to climate change, Current Biology, 17(4), 360-365.

Kennedy, E. V., Perry, C. T., Halloran, P. R., Iglesias-Prieto, R., Schönberg, C. H., Wisshak, M., ... \& Mumby, P. J. (2013). Avoiding coral reef functional collapse requires local and global action. Current Biology, 23(10), 912918.

Koweek, D., R.B. Dunbar, J.S. Rogers, G.J. Williams, N. Price, D. Mucciarone, and L. Teneva (2015), Environmental and ecological controls of coral community metabolism on Palmyra Atoll, Coral Reefs 34, 339-351.

PeerJ reviewing PDF | (2018:01:23723:3:2:NEW 18 Oct 2018) 
659

660

661

662

663

664

665

666

667

668

669

670

671

672

673

674

675

676

677

678

679

680

681

682

683

684

685

686

687

688

689

690

691

692

693

694

695

696

697

698

699

700

701

702

703

704

705

706

707

708

709

710

711

712

713

Kleypas, J.A., R.W. Buddemeier, D. Archer, J.P. Gattuso, C. Langdon, and B.N. Opdyke, 1999. Geochemical consequences of increased atmospheric carbon dioxide on coral reefs, Science 284(5411), 118-120.

Lirman, D., N.R. Gracias, B.E. Gintert, A.C.R. Gleason, R.P. Reid, S. Negahdaripour, and P. Kramer (2007), Development and application of a video-mosaic survey technology to document the status of coral reef communities, Environmental monitoring and Assessment 125(1-3), 59-73.

Liu, X., Byrne, R. H., Lindemuth, M., Easley, R., \& Mathis, J. T. (2015). An automated procedure for laboratory and shipboard spectrophotometric measurements of seawater alkalinity: Continuously monitored single-step acid additions. Marine Chemistry, 174(C), 141-146. http://doi.org/10.1016/j.marchem.2015.06.008

Ludeman, D. A., Reidenbach, M. A., \& Leys, S. P. (2017). Correction: The energetic cost of filtration by demosponges and their behavioural response to ambient currents. Journal of Experimental Biology, 220(24), 4743-4744.

McCook, L.J. (1999), Macroalgae, nutrients and phase shifts on coral reefs: scientific issues and management consequences for the Great Barrier Reef, Coral Reefs 18, 357-367.

McGillis, W. R., Langdon, C., Loose, B., Yates, K. K., \& Corredor, J. (2011). Productivity of a coral reef using boundary layer and enclosure methods. Geophysical Research Letters, 38(3), n/a-n/a. http://doi.org/10.1029/2010GL046179

McMahon, A., Santos, I. R., Cyronak, T., \& Eyre, B. D. (2013). Hysteresis between coral reef calcification and the seawater aragonite saturation state. Geophysical Research Letters, 40(17), 4675-4679.

McMurray, S. E., Stubler, A. D., Erwin, P. M., Finelli, C. M., \& Pawlik, J. R. (2018). A test of the sponge-loop hypothesis for emergent Caribbean reef sponges. Marine Ecology Progress Series, 588, 1-14.

Middelburg, Jack J., Carlos M. Duarte, and Jean-Pierre Gattuso. "Respiration in coastal benthic communities." Respiration in aquatic ecosystems. Oxford University Press, Oxford (2005): 206-224.

Mintrop L, Pérez FF, González-Dávila M, Santana-Casiano JM, Körtzinger A (2000) Alkalinity determination by potentiometry: Intercalibration using three different methods. Cienc Mar 26:23-37

Newman, M. J., Paredes, G. A., Sala, E., \& Jackson, J. B. (2006). Structure of Caribbean coral reef communities across a large gradient of fish biomass. Ecology letters, 9(11), 1216-1227.

Murphy, G. N., Perry, C. T., Chin, P., \& McCoy, C. (2016). New approaches to quantifying bioerosion by endolithic sponge populations: applications to the coral reefs of Grand Cayman G. N. Murphy, C. T. Perry, P. Chin \& C. McCoy. Coral Reefs, 1-15. http://doi.org/10.1007/s00338-016-1442-z

Odum, H. T., \& Hoskin, C. M. (1958). Comparative studies on the metabolism of marine waters. Publications of the Institute of Marine Science, Texas, 5, 16-46.

Okazaki, R.R., P.K. Swart, C. Langdon (2013), Stress-tolerant corals of Florida Bay are vulnerable to ocean acidification. Coral Reefs 32, 671-683.

Patterson, M.R., K.P. Sebens, R.R. Olson (1991). In situ measurements of flow effects on primary production and dark respiration in reef corals. Limnology and Oceanography 36(5), 936-948.

Paerl, H. W., \& Paul, V. J. (2012). Climate change: links to global expansion of harmful cyanobacteria. Water research, 46(5), 1349-1363.

Perry CT, Spencer T, Kench PS (2008). Carbonate budgets and reef production states: a geomorphic perspective on the ecological phase-shift concept. Coral Reefs 27:853-866

Perry CT, Murphy GN, Kench PS, Smithers SG, Edinger EN, Steneck RS, Mumby PJ (2013). Caribbean-wide decline in carbonate production threatens coral reef growth. Nature communications. 4:1402.

Perry CT, Murphy GN, Graham NA, Wilson SK, Januchowski-Hartley FA, East HK (2015a). Remote coral reefs can sustain high growth potential and may match future sea-level trends. Scientific reports 5:18289

Porter, J.W., and O.W. Meier (1992), Quantification of loss and change in Floridian reef coral populations, American Zoologist 32(6), 625-640.

Redfield, A. C. (1963). The influence of organisms on the composition of seawater. The sea, 2, 26-77.

Roche, D. G., S. A. Binning, Y. Bosiger, J. L. Johansen, and J. L. Rummer (2013), Finding the best estimates of metabolic rates in a coral reef fish, Journal of Experimental Biology, 216(11), 2103-2110, doi: $10.1242 /$ jeb.082925.

Shaw, E. C., McNeil, B. I., \& Tilbrook, B. (2012). Impacts of ocean acidification in naturally variable coral reef flat ecosystems. Journal of Geophysical Research: Oceans, 117(C3).

Shaw, E.C., S.R. Phinn, B. Tilbrook, and A. Steven (2014), Comparability of slack water and Lagrangian flow respirometry methods for community metabolic measurements, PLoS One 9(11), e112161, doi:10.1371/journal.pone.0112161.

Shaw, E. C., Phinn, S. R., Tilbrook, B., \& Steven, A. (2015). Natural in situ relationships suggest coral reef calcium carbonate production will decline with ocean acidification. Limnology and Oceanography, 60(3), 777-788.

Peer] reviewing PDF | (2018:01:23723:3:2:NEW 18 Oct 2018) 
714

715

716

717

718

719

720

721

722

723

724

725

726

727

728

729

730

731

732

733

734

735

736

737

738

739

740

741

742

743

744

745

746

747

748

749

750

751

752

753

754

755

756

757

758

759

760

761

762

763

764

765

766

767

768

769

Silbiger, N. J., \& Donahue, M. J. (2015). Secondary calcification and dissolution respond differently to future ocean conditions. Biogeosciences, 12(2), 567-578.

Smith, S. V., \& Key, G. S. (1975). Carbon dioxide and metabolism in marine environments 1. Limnology and Oceanography, 20(3), 493-495.

Takeshita, Y., McGillis, W., Briggs, E.M., Carter, A.L., Donham, E.M., Martz, T.R., Price, N.N. \& Smith, J.E., 2016. Assessment of net community production and calcification of a coral reef using a boundary layer approach. Journal of Geophysical Research: Oceans, 121(8), pp.5655-5671.

Webb, A.E., S.M.A.C. van Heuven, D. de Bakker, F.C. van Duyl, G-J. Reichart, \& L.J. de Nooijer Lennart (2017). Combined Effects of Experimental Acidification and Eutrophication on Reef Sponge Bioerosion Rates. Frontiers in Marine Science (4) 311. doi:10.3389/fmars.2017.00311

Wild, C., Huettel, M., Klueter, A., Kremb, S. G., Rasheed, M. Y., \& Jørgensen, B. B. (2004). Coral mucus functions as an energy carrier and particle trap in the reef ecosystem. Nature, 428(6978), 66.

Wisshak, M., Schönberg, C. H. L., Form, A., \& Freiwald, A. (2013). Effects of ocean acidification and global warming on reef bioerosion-lessons from a clionaid sponge. Aquat Biol. 19 (2): 111-127.

Wood, B. L. (1967). Geology of the Cook Islands. New Zealand journal of geology and geophysics, 10(6), 1429-1445.

Yates, K. K., \& Halley, R. B. (2003). Measuring coral reef community metabolism using new benthic chamber technology. Coral Reefs, 22(3), 247-255. http://doi.org/10.1007/s00338-003-0314-5

Yates, K. K., Zawada, D. G., Smiley, N. A., Tiling-Range, G. (2017) Divergence of seafloor elevation and sea level rise in coral reef ecosystems. Biogeosciences, 15;14(6):1739.

Table S1. ReefBudget method applied to the $4.4 \mathrm{~m}^{2}$ full planar surface of the tent. [Calcification Rate] = [Cover] * [Specific Calcification Rate $] *$ [Rugosity] and $\mathrm{NCC}_{\text {ReetBudget }}=[$ Total Coral Calcification $]+[$ Total CCA

Calcification] - [Total Microbioerosion]

Table S2. Surface area of substrate classes.

Table S3. Rugosity. Planar areas were determined from photogrammetry, based on photographs collected after incubator removal at end of the experiment. Rugosity of 1.36 was determined in the field after removal. Rugosity of the sandy part of the patch was assumed to be approximately 1.00. Average rugosity of the patch is calculated.

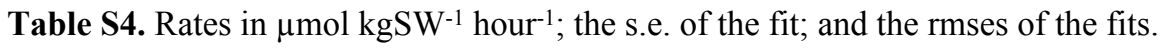

Table S5. Comparison of rates of change in $\mathrm{O} 2$ concentrations inferred from either the full $\mathrm{O}_{2}$ concentration history (third column) or from only the first 30 minutes of each incubation (rightmost column). The latter method provides a more consistent separation between day- and night time incubations (especially when ignoring incubation 1). The daytime average $\mathrm{O}_{2}$ consumption is $\sim 20 \%$ below the night time rate.

Figure S1. Example of results of the 'Monte Carlo' method used to assess robustness of inferred time rates of change of concentrations during incubation. Here, measured values of $A_{T}$ and the leak rate are varied slightly $\left( \pm 4 \mu \mathrm{mol} \mathrm{kg}^{-1}\right.$ for $\mathrm{A}_{\mathrm{T}}, \pm 0.1 \% \mathrm{~min}^{-1}$ for leak rate), and curves are repeatedly fit. The average and standard deviation of one thousand such fits are presented. In this example, the rate average is slightly larger than the associated uncertainty, and the rate is thus assumed to be significantly different from zero.

Figure S2 Interior and ambient nutrient concentrations

Figure S3. In-tent measurements and model fits of all five incubation periods. Second and fourth incubations were during nighttime. The legend presented in the third row of panels applies to all subsequent rows (except PAR, which was measured).

Figure S4. Data from secondary 'pyramid' incubator, placed on bare sediment. The observed trends are the result of the (unknown) balance between (i) exchange with the environment and (ii) sedimentary processes. Irrespective of dominant process, sedimentary fluxes are inferred to be negligibly low compared to those observed in the primary incubator (see main text). 


\section{Figure 1}

Area where the experimental enclosure was achieved with a schematic outline of the tent incubation.

(a) Photograph depicting tent, umbilical cord, support divers and the dingy used for sample collection. (b) Schematic layout of the tent and surroundings. The Island of Saba is located to the east of this location. (c) Schematic side view of the employed setup for enclosure of a small patch of coral reef. The central structure is a rigid, inflatable dome tent, held securely in place by lead bricks and guy-lines (not shown). Inside the tent are located a battery powered mixing propeller for maintaining water circulation, and analyzers for salinity (S), temperature $(\mathrm{T})$, oxygen $\left(\mathrm{O}_{2}\right)$ and PAR. External to the enclosure are located another $\mathrm{S} / \mathrm{T}$ analyzer, a current profiler and a pump (powered intermittently from the surface) which through an umbilical cord delivers enclosure interior water to the sea surface for sampling. Sampling of exterior water was performed either by this pump (with SCUBA divers temporarily disconnecting the connection to the tent interior) or by divers using large volume syringes. Zippers allow for opening of tent windows for re-equilibrating interior and exterior conditions between incubations. 

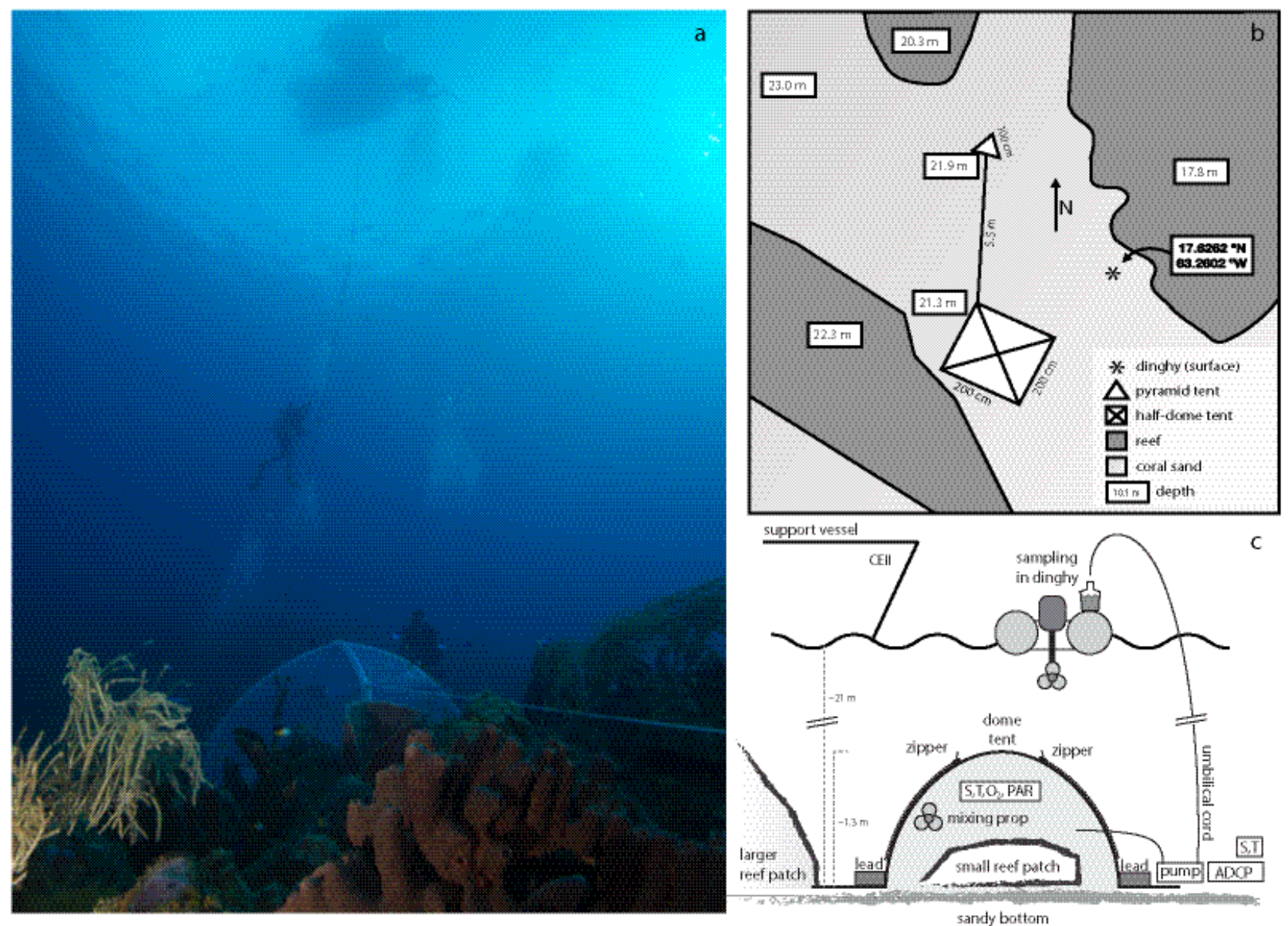
Figure 2

Overview of the enclosed coral patch, after removal of tent at end of experiment.

Overview of the enclosed coral reef patch, after termination of the tent incubation. Yellow lines mark the extent of the tent (approximately $2 \times 2 \mathrm{~m}$ ). 


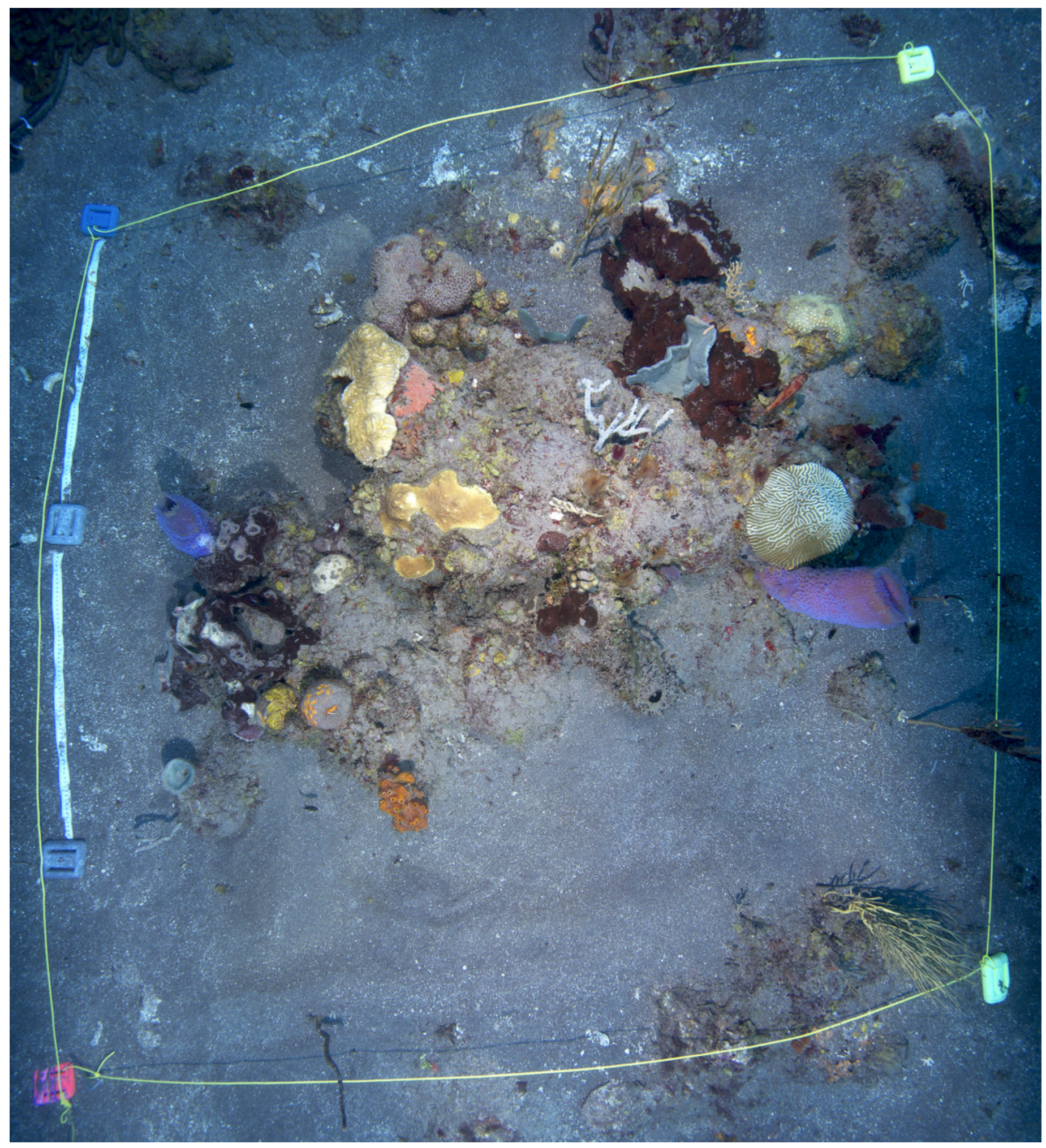


Figure 3 (on next page)

Measured conditions within and outside the tent

(a) Salinity and temperature recorded outside the enclosure show occasional mixing of a cool, saline deep water body into the warmer, fresher surface water component that is most commonly observed at the depth of the enclosure (as indicated by the high density of data points at $S \sim 34.8)$. (b, d, f) Regression against salinity of, respectively, $A_{T}, C_{T}$ and $O_{2}$. Samples in these regressions originate from three sources (two for $\mathrm{O}_{2}$ ). (c, e, g) Measured values of, respectively $A_{T}, C_{T}$ and $O_{2}$, plotted together with time trace of these values, generated from the regressions against salinity. 


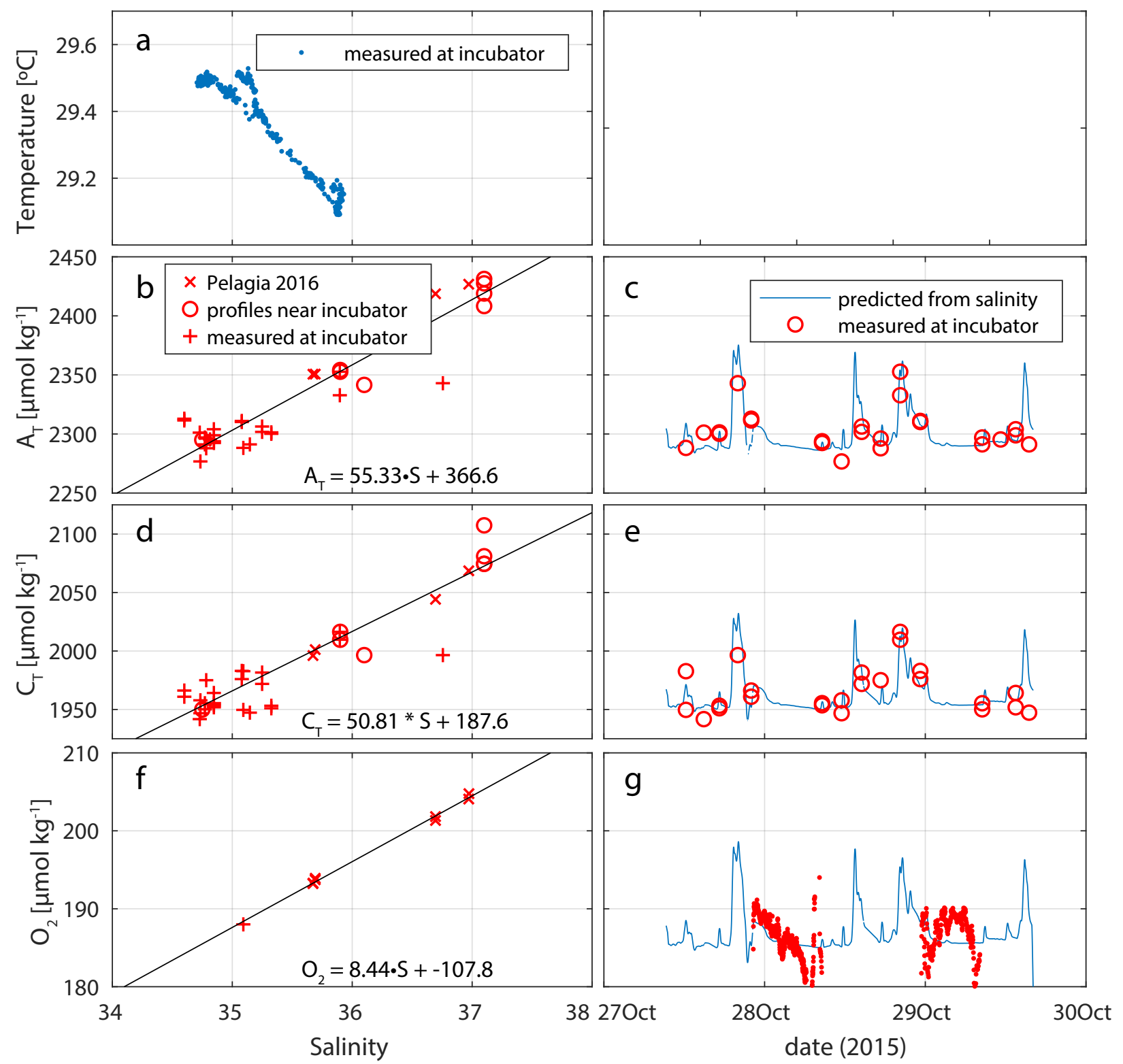




\section{Figure 4 (on next page)}

Results of the model employed to infer the input rates from observations

Illustrative results of the model (bold red line) employed to infer the substance input rates from observations, here for incubation 4. (a) A water exchange rate of $0.007 \mathrm{~min}^{-1}$ between enclosure and environment optimally relates ambient and interior measurements of salinity. Back-calculating ambient salinity from interior salinity is shown here to be feasible. (b) Ambient temperature co-varies with $\mathrm{S}$. From $\mathrm{T}$, the exchange rate is inferred to be $0.012 \mathrm{~min}$ 1 (higher than from $\mathbf{S}$ due to additional conductive equilibration). Additionally, in (c-f), we present results of a simplistic asymptotic curve fitting (thin red line) to show how the two methods may diverge appreciably, here mostly evidently for $A_{T}$. (Note that the uncertainty of the asymptotic fit is worse than that of the model used in this study). 

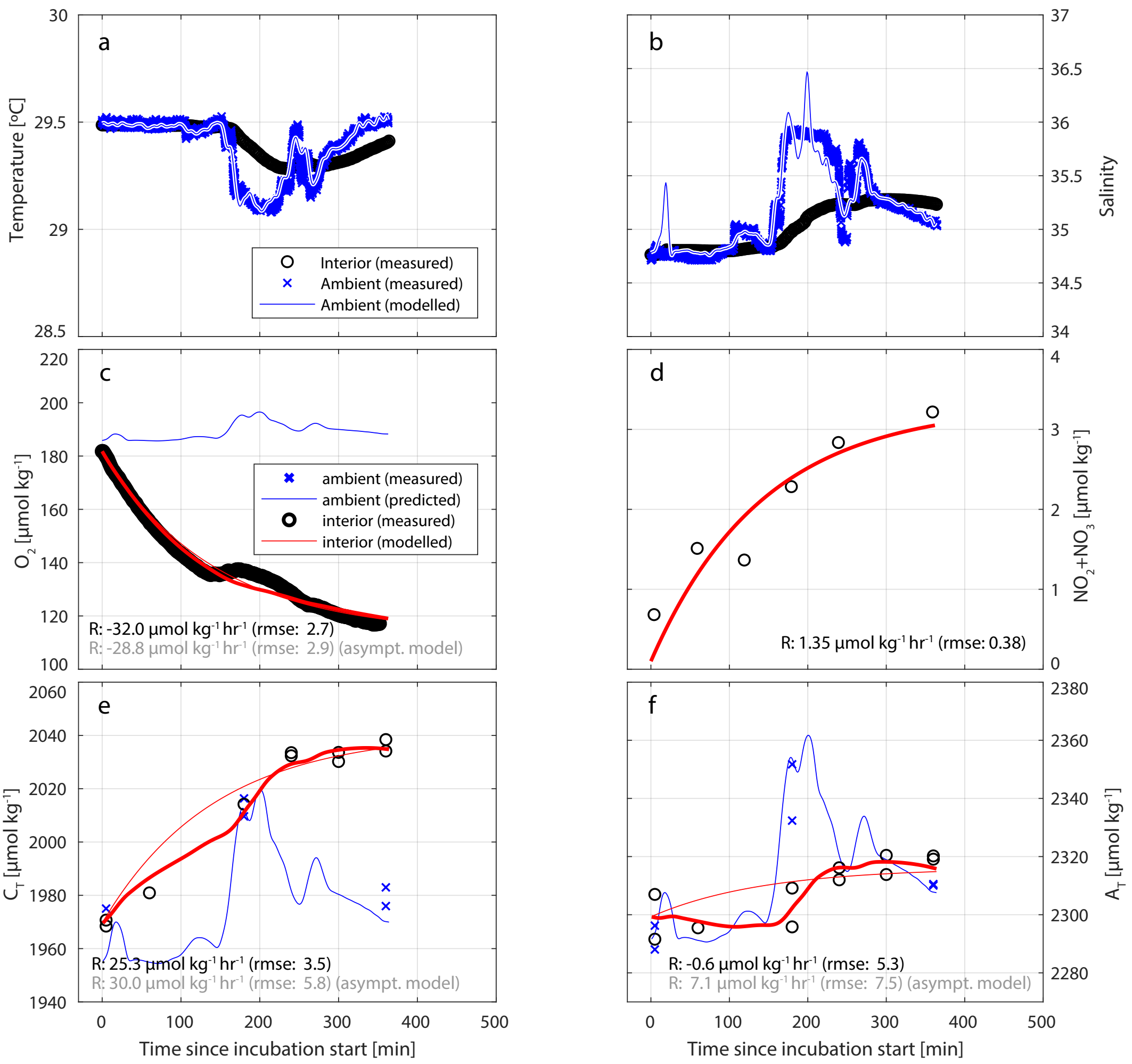


\section{Table $\mathbf{1}$ (on next page)}

Timing of the five incubations

Incubation starting and end times, duration and light. The listed PAR values are in $\mu \mathrm{mol}$ quanta $\mathrm{m}^{-2} \mathrm{~s}^{-1}$. 


\begin{tabular}{|c|c|c|c|c|c|}
\hline Incubation & 1 & 2 & 3 & 4 & 5 \\
\hline latitude & $17.6261^{\circ} \mathrm{N}$ & & & & \\
\hline longitude & $63.2602^{\circ} \mathrm{W}$ & & & & \\
\hline depth (m) & 21 & & & & \\
\hline start (local time) & Oct $27,09: 17$ & Oct $27,17: 10$ & Oct $28,08: 33$ & Oct $28,17: 15$ & Oct $29,08: 10$ \\
\hline end (local time) & Oct $27,14: 59$ & Oct $27,22: 13$ & Oct $28,14: 47$ & Oct $28,23: 20$ & Oct $29,16: 10$ \\
\hline duration (min) & 342 & 303 & 374 & 365 & 480 \\
\hline light mean (PAR) & 65 & 3 & 58 & 3 & 91 \\
\hline std & 23 & 1 & 14 & 1 & 15 \\
\hline $\min$ & 22 & 2 & 11 & 2 & 5 \\
\hline $\max$ & 120 & 8 & 75 & 8 & 161 \\
\hline
\end{tabular}

1 


\section{Table 2 (on next page)}

Summary of fluxes inferred

Summary of fluxes inferred from observed concentration changes in the enclosure during each of five incubation periods. Non-significant fluxes are greyed out. See text for methods for derivation of rates and uncertainties. All fluxes in $\mathrm{mmol} \mathrm{hour}^{-1} \mathrm{~m}^{-2}$ (planar incubated surface area). Negative dissolution fluxes are described (instead of positive calcification) to maintain co-directionality of the fluxes of respiration and dissolution. 
1

\begin{tabular}{lccccc}
\multicolumn{1}{c}{ Incubation } & 1 & 2 & 3 & 4 & 5 \\
$\mathrm{PO}_{4}$ & $0.015 \pm 0.004$ & $0.009 \pm 0.005$ & $0.016 \pm 0.005$ & $0.031 \pm 0.009$ & $0.037 \pm 0.007$ \\
$\mathrm{NO}_{2}+\mathrm{NO}_{3}$ & $0.49 \pm 0.14$ & $0.55 \pm 0.21$ & $0.83 \pm 0.09$ & $0.91 \pm 0.18$ & $0.81 \pm 0.20$ \\
$\mathrm{NH}_{4}$ & $0.21 \pm 1.06$ & $0.26 \pm 0.48$ & $0.18 \pm 0.05$ & $0.23 \pm 0.04$ & $0.17 \pm 0.19$ \\
$\mathrm{NO}_{2}$ & $0.02 \pm 0.01$ & $0.01 \pm 0.01$ & $0.02 \pm 0.00$ & $0.02 \pm 0.00$ & $0.01 \pm 0.01$ \\
$\mathrm{SIL}$ & $0.44 \pm 0.10$ & $0.00 \pm 0.18$ & $0.19 \pm 0.10$ & $-0.07 \pm 0.20$ & $-0.02 \pm 0.15$ \\
$\mathrm{DOC}$ & $1.4 \pm 4.3$ & $-1.1 \pm 4.2$ & $-0.9 \pm 4.8$ & $-1.9 \pm 2.8$ & $-0.1 \pm 5.4$ \\
$\mathrm{O} 2$ & $-9.0 \pm 0.7$ & $-13.5 \pm 1.1$ & $-13.6 \pm 1.3$ & $-21.7 \pm 1.9$ & $-17.0 \pm 1.6$ \\
$\mathrm{C}_{\mathrm{T}}$ & $5.0 \pm 0.7$ & $11.1 \pm 0.9$ & $13.0 \pm 1.1$ & $17.1 \pm 1.6$ & $11.7 \pm 1.2$ \\
$\mathrm{~A}_{\mathrm{T}}$ & $0.5 \pm 0.6$ & $-2.5 \pm 0.9$ & $-2.8 \pm 0.6$ & $-0.4 \pm 0.8$ & $0.4 \pm 0.5$ \\
$\mathrm{C}_{\text {Tresp }}$ & $4.8 \pm 0.0$ & $12.3 \pm 0.0$ & $14.4 \pm 0.0$ & $17.3 \pm 0.0$ & $10.4 \pm 0.0$ \\
$\mathrm{~A}_{\text {Tresp }}$ & $0.0 \pm 0.0$ & $0.0 \pm 0.0$ & $0.0 \pm 0.0$ & $0.0 \pm 0.0$ & $0.0 \pm 0.0$ \\
$\mathrm{C}_{\text {Tdiss }}$ & $0.2 \pm 0.0$ & $-1.2 \pm 0.0$ & $-1.4 \pm 0.0$ & $-0.2 \pm 0.0$ & $0.2 \pm 0.0$ \\
$\mathrm{~A}_{\text {Tdiss }}$ & -0.57 & 2.85 & 3.2 & 0.46 & -0.46
\end{tabular}

2 


\section{Table 3(on next page)}

Net community calcification from flux-based and ReefBudget method.

NCC of the planar total area inside the incubation calculated from fluxes and the ReefBuget method. 
1

$\begin{array}{lccccc}\text { Incubation } & 1 & 2 & 3 & 4 & 5 \\ \mathrm{NCC}_{\text {[this study] }}\left(\mathrm{kg} \mathrm{CaCO}_{3} \mathrm{~m}^{-2} \mathrm{yr}^{-1}\right) & -0.5 & 2.5 & 2.8 & 0.4 & -0.4 \\ \mathrm{NCC}_{\text {ReerBudget }}\left(\mathrm{kg} \mathrm{CaCO}_{3} \mathrm{~m}^{-2} \mathrm{yr}^{-1}\right) & 0.36 & 0.36 & 0.36 & 0.36 & 0.36 \\ \mathrm{NCC}_{\text {[this study] }}\left(\mathrm{mmol} \mathrm{CaCO}_{3} \mathrm{~m}^{-2} \mathrm{~h}^{-1}\right) & -0.57 & 2.85 & 3.2 & 0.46 & -0.46 \\ \mathrm{NCC}_{\text {ReerBudget }}\left(\mathrm{mmol} \mathrm{CaCO}_{3} \mathrm{~m}^{-2} \mathrm{~h}^{-1}\right) & 0.41 & 0.41 & 0.41 & 0.41 & 0.41\end{array}$

2 


\section{Table 4 (on next page)}

Stoichiometry of rates observed during 5 incubations

Stoichiometry of rates observed during 5 incubations. Values in column "avg." are calculated as the ratio of the sums of incubations 2-5. Uncertainties are calculated by error propagation. Rightmost two columns show literature values from (i) Redfield et al (1963) and (ii) Atkinson and Smith (1983), representing the elemental compositions of (i) marine phytoplankton and (ii) benthic macroalgae. Our incubation results most closely resemble the latter. 
1

$\begin{array}{ccccccccc}\text { Incubation } & 1 & 2 & 3 & 4 & 5 & \text { all } & \mathrm{R}_{1963} & \mathrm{~A}_{\&} \mathrm{~S}_{1983} \\ \mathrm{P} & 1 & 1 & 1 & 1 & 1 & 1 & 1 & 1 \\ \mathrm{~N} & 32.8 \pm 12.2 & 61.2 \pm 42.1 & 51.5 \pm 17.9 & 29.7 \pm 10.7 & 21.7 \pm 6.5 & 33.2 \pm 5.6 & 16 & 30 \\ \mathrm{O} & 337.5 \pm 99.7 & 1222.4 \pm 714.9 & 805.8 \pm 275.4 & 557.9 \pm 175.1 & 313.3 \pm 60.8 & 535.6 \pm 73.3 & 106 & 550 \\ \mathrm{C} & -608.7 \pm 157.5 & -1485.3 \pm 867.5 & -842.9 \pm 289.4 & -706.6 \pm 223.6 & -455.2 \pm 91.6 & -691.7 \pm 94.9 & -150 & -610 \\ \mathrm{O} / \mathrm{C} & -1.80 \pm 0.33 & -1.22 \pm 0.14 & -1.05 \pm 0.13 & -1.27 \pm 0.14 & -1.45 \pm 0.18 & -1.29 \pm 0.07 & 1.22 & ?\end{array}$

2 